OPEN ACCESS

Edited by:

Kirankumar Mysore,

The Samuel Roberts Noble

Foundation, USA

Reviewed by:

Youn-Sig Kwak,

Gyeongsang National University,

South Korea

Harsh Bais,

University of Delaware, USA

*Correspondence.

Jian-Hua Guo

jhguo@njau.edu.cn

tPresent address:

Chun-Hao Jiang,

Zhi-Hang Fan, Ping Xie and

Jian-hua Guo,

Like Building, NAU, 1" , Weigang,

Xuanwu, Nanjing 210095, China

¥ These authors have contributed equally to this work.

Specialty section:

This article was submitted to Plant Biotic Interactions, a section of the journal Frontiers in Microbiology

Received: 05 February 2016 Accepted: 21 April 2016 Published: 09 May 2016

Citation:

Jiang C-H, Fan Z-H, Xie P and Guo

J-H (2016) Bacillus cereus AR156 Extracellular Polysaccharides Served

as a Novel Micro-associated

Molecular Pattern to Induced Systemic Immunity to Pst DC3000 in Arabidopsis.

Front. Microbiol. 7:664. doi: 10.3389/fmicb.2016.00664

\section{Bacillus cereus AR156 Extracellular Polysaccharides Served as a Novel Micro-associated Molecular Pattern to Induced Systemic Immunity to Pst DC3000 in Arabidopsis}

\author{
Chun-Hao Jiang ${ }^{\dagger \neq}$, Zhi-Hang Fan ${ }^{\dagger \neq}$, Ping $\mathrm{Xie}^{\dagger}$ and Jian-Hua Guo ${ }^{\star \neq}$
}

Key Laboratory of Monitoring and Management of Crop Diseases and Pest Insects, Department of Plant Pathology, College of Plant Protection, Ministry of Agriculture, Engineering Center of Bioresource Pesticide in Jiangsu Province, Nanjing Agricultural University, Nanjing, China

Non-host resistance (NHR) is a broad-spectrum plant defense. Upon colonizing on the surface on the root or leaves of non-host species, pathogens initial encounter preform and induce defense response in plant, such as induced hypersensitive response, PAMPs triggered immunity $(\mathrm{PTI})$, and effector triggered immunity (ETI). The ability of plants to develop an induced systemic response (ISR) in reaction to the colonization by non-pathogenic rhizobacterium depends on interactions between host plants and the colonizing rhizobacterium, and the ISR also can be defined as a NHR. However, how the colonization signal is and how systemic resistance to pathogens is developed is still unclear. In this study, we demonstrated that the extracellular polysaccharides (EPSs) of Bacillus cereus AR156 could act as novel microbe-associated molecular patterns (MAMPs) and function in the early perception status of the ISR of $B$. cereus AR156. The results revealed that $B$. cereus AR156 EPS could induce systemic resistance to Pst DC3000 in Arabidopsis. Cellular defense response markers such as hydrogen peroxide accumulation, callose deposition, and defense-associated enzyme were induced upon challenge inoculation in the leaves primed by EPS. Moreover, the defense-related genes $P R 1, P R 2$, and PR5 and mitogen-activated kinases (MAPK) cascade marker gene MPK6 were concurrently expressed in the leaves of EPS-treated plants and induced higher resistance to Pst DC3000 in Col-0 than that in the jar1 or etr1 mutants. The protection was absent in the NahG transgenic plants and npr1 mutant, suggesting an activation of the salicylic acid (SA)- and the MAPK-dependent signaling pathways with NPR1-dependent by B. cereus AR156 EPS. In conclusion, B. cereus AR156 EPS play an important role in MAMP perception during the process of rhizobacteria-triggered NHR. This study is the first to illustrate how AR156 induces systemic resistance to Pst DC3000 in Arabidopsis. It also provides the first explanation of how plants perceive colonization of non-pathogenic bacteria and how rhizobacteria trigger ISR to plant pathogens.

Keywords: induced systemic resistance (ISR), non-host resistance, micro-associated molecular patterns (MAMPs), extracellular polysaccharides, Bacillus cereus (AR156), biological control 


\section{INTRODUCTION}

Plant growth is influenced by a variety of biotic and abiotic factors. To survive from an antagonistic and complex environment, the plant has evolved a series of inducible defense mechanisms, which can assist them to activate appropriate defense reactions upon pathogen invasion (Niu et al., 2011; Jiang et al., 2015). Well-researched examples of plant-induced resistance include SAR and rhizobacteria-ISR, which are phenotypically similar to each other and both of them can be defined as a non-host resistance (NHR) (Conrath et al., 2002; Jiang et al., 2015). NHR is one kind of resistance exhibited by an entire plant species to all genetic variants of a non-adapted pathogen species in nature. Phyto-hormones such as SA, JA, and ethylene play important but quite different roles in the signaling network, which function on regulating the development of ISR and SAR (Glazebrook, 2001; Niu et al., 2011). As previously reported, the SAR is induced by SA, and its onset involves both systemic and local increases in endogenously synthesis of phytohormones SA, leading to activation of pathogenesis-related (PR) proteins encoding genes, such as $P R 1, P R 2$, and PR5 (Ward et al., 1991; Van Loon and Van Strine, 1999; Niu et al., 2011; Jiang et al., 2015). In contrast, ISR requires the JA and ET signaling pathways (Van Loon et al., 1998; Jiang et al., 2015) and is combined with the high expression of the plant defensin 1.2 (PDF1.2) (Van Oosten et al., 2008; Jiang et al., 2015).

Induced systemic response has been found and demonstrated in series of plant species [e.g., cucumber (Cucumis sativus), bean (Phaseolus vulgaris), and tomato (Solanum lycopersicum) (Van Loon et al., 1998; Van der Ent et al., 2008; Jiang et al., 2015)]. The rhizobacterium Pseudomonas fluorescens WCS417r (WCS417r hereafter) has been demonstrated, which could trigger ISR in series of plant species (Pieterse et al., 2002). Nevertheless, it has also been documented that Bacillus cereus AR156 induces systemic resistance in Arabidopsis (Niu et al., 2011). The ability of plants to trigger ISR in response to the root colonization by nonpathogenic rhizobacterium relies on the interactions between host plants and the rhizobacterium (Van Loon et al., 1998; Pieterse et al., 2002), which rises following questions: How do plants perceive the colonization of non-pathogenic bacteria? How do bacteria colonizing plant roots trigger ISR to plant pathogens in systemic tissue?

Plants are equipped with a multiple of immune receptors, which can sense the invasion of numerous pathogenic microbes (Boller and Felix, 2009; Dodds and Rathjen, 2010; Monaghan and Zipfel, 2012; Spoel and Dong, 2012; Li et al., 2014). At the front line, plants have two main modes functions on pathogen recognition. The first mode was pattern recognition receptors (PRRs), which localized on the plasma membrane and function on the recognition of pathogen/microbe-associated molecular patterns (PAMPs/MAMPs). Most of these conserved signatures

Abbreviations: dpi, Day post inoculation; dpt, Day post treatment; EPS, Extracellular polysaccharides; hpi, Hour post inoculation; HR, Hypersensitive response; ISR, Induced systemic resistance; JA, Jasmine acid; MAMPs, Microassociated molecular patterns; MAPK, Mitogen-activated protein kinases; Pst DC3000, Pseudomonas syringae pv. tomato DC3000; SAR, Systemic acquired resistance; SA, Salicylic acid. are belongs to the essential microbial structures, such as flagellin of bacteria, cell walls and translation factors (Boller and Felix, 2009; Mari-Anne et al., 2013; Newman et al., 2013; Sreekanta et al., 2015; Trdá et al., 2015). The endogenous signals may cause similar responses to pathogen, which was called damageassociated molecular patterns (DAMPs). These signals include oligogalacturonides (OGs) and cutin monomers, which could act as a critical component of signaling in signaling tranduction (Kauss et al., 1999; Huffaker and Ryan, 2007; Yamaguchi et al., 2010; Rasul et al., 2012; Bartels et al., 2013; Sreekanta et al., 2015).

Host resistance responses induced by MAMPs are collectively referred to as pattern-triggered immunity (PTI) (Jones and Takemoto, 2004; Zhang and Zhou, 2010). In pattern-triggered immunity, the defense responses are motivated following by the recognition of pathogen PAMPs, such as flg22, which is a conserved 22 amino acid N-terminal sequence of the bacterial flagellin protein. In Arabidopsis, flg22 has been well studied and perceived by PRRs such as FLAGELLIN-SENSITIVE 2 (FLS2). Recent studies have shown that PTI also plays an important role in NHR. For example, the flagellin of biocontrol strain, which can act as MAMPs and recognized by PRRs also can trigger ISR. Meziane and asscociate reporte that the isolated flagellin of P. putida WCS358 was shown to trigger ISR against Pst DC3000 in Arabidopsis, as well as an Lipopolysaccharides (LPS) from $P$. fluorescens WCS417r and P. putida WCS358 (Meziane et al., 2005). Beside the flagellin, the bacterial Lipopolysaccharides also can act as a prototypical PAMP which can induce series of plant defense-related responses, such as the nitric oxide (NO) generation, oxidative burst, the cell-wall alteration, callose deposition, and the expression of PR gene (Sun and Li, 2013).

Zhang et al. (2007) and associates reported that the reactive oxygen species (ROS) production in the process of PTI was mediated primarily by the NADPH oxidase RBOHD, which was necessary for callose deposition (Torres et al., 2002; Sreekanta et al., 2015). The following responses included production of $\mathrm{SA}$, JA, and ET, the expression level of defense-related gene changes (van Loon et al., 2006; Browse, 2009; Vlot et al., 2009; Sreekanta et al., 2015). Many studies have reported that phyto-hormones SA, JA, and ET play important roles in the signaling network on regulating the development of ISR. As we all known, some beneficial rhizobacteria can trigger ISR by priming the plant for potentiated activation of several cellular defense responses. The potentiated responses include oxidative burst, callose deposition (Iriti et al., 2003), defense-related enzymes accumulation (Benhamou and Belanger, 1998), and some secondary metabolites production (Yedidia et al., 2003). Therefore, here we raised a question: Is there a crucial part of microbial structures that could act as a type of MAMP that could be perceived by plants and trigger ISR to the pathogen?

Microorganisms have evolved in various responses to biotic and abiotic stress and interact with their environments (Pintor et al., 2012; Singh et al., 2012; Huang and Liu, 2013). An efficient response mechanism is the EPS hereafter secretion (Wei et al., 2011; Wang et al., 2014). A series of studies have reported that EPS act as highly potent and efficient signatures that can perceive environment signals and interact with plants. We propose that the EPS of rhizobacteria can act as MAMPs and facilitate 
the induction of systemic resistance in some rhizobacteria to pathogens in plants.

We previously isolated the rhizobacterium $B$. cereus strain AR156. In our previous study, it was found that colonization of Arabidopsis roots by AR156 could enhance resistance against a broad-spectrum disease. We further demonstrated that AR156 could elicit ISR through simultaneously activating of the SA and JA/ET two signaling pathways (Niu et al., 2011). To further investigate how plants perceive the colonization of nonpathogenic bacteria and how bacteria trigger ISR to plant pathogens, we carried out the current study by using a wellestablished system employing ISR-inducing $B$. cereus strain AR156 and a plant-pathogen interacting system (Arabidopsis and Pst DC3000), a common practice in our lab over the past few years (Ref).

In this study, we demonstrated that B. cereus AR156 EPS could act as novel MAMPs during rhizobacterium-ISR that functioned to distinguish between the rhizobacterium and plant. Results showed that the $B$. cereus AR156 EPS could be perceived by Arabidopsis, which activated the downstream immune response, including the activation of various cellular defense responses and changes in gene expression encoding PR proteins [PR1, $P R 2, P R 5]$ through the MAPK- and SA-signaling pathways. The B. cereus AR156 EPS-triggered ISR was dependent on an ankyrin repeat protein, NPR1 (non-expresser of PR genes 1)/NIM1 (noninducible immunity). This study is the first to illustrate and provide a clear explanation regarding how the plant perceives the colonization of non-pathogenic bacteria and triggers ISR to plant pathogens when the pathogens are localized on the surface of the plant root.

\section{MATERIALS AND METHODS}

\section{Plants, Bacterial Strains, and Growth Conditions}

The following Arabidopsis lines were used: Col-0 (wild-type Arabidopsis thaliana ecotype); npr1 (Bowling et al., 1994); signaling mutants jar1 (Staswick et al., 1992); and etr1 (Bleecker et al., 1988) and a transgenic line NahG (overe-expressing the bacterial NahG gene in Col-0) (Delaney et al., 1994); All Seeds of Arabidopsis lines were sown in an soil combined with sterilized vermiculite and potting soil, and the 2 -week-old seedlings were transferred into $200 \mathrm{ml}$ pots, which filled with a mixture of sterilized vermiculite and potting soil, each pot placed one seedling. All the plants were cultivated in a growth chamber with a suitable condition, which was $10 \mathrm{~h}$ day $\left(200 \mu \mathrm{E} \mathrm{m} \mathrm{m}^{-2} \mathrm{~s}^{-1}\right.$ at $\left.22^{\circ} \mathrm{C}\right)$ and a $14 \mathrm{~h}$ night $\left(20^{\circ} \mathrm{C}\right)$ cycle at $70 \%$ relative humidity and the whole growth process was supplied with modified half-strength Hoagland nutrient solution weekly (Hoagland and Arnon, 1938).

The studied PGPR strain B. cereus AR156 was cultivated on $\mathrm{LB}$ (Luria-Bertani) (yeast extract $5 \mathrm{~g}$, peptone $10 \mathrm{~g}, \mathrm{NaCl} 10 \mathrm{~g}$ in $1 \mathrm{~L}$ of water) agar plates at $28^{\circ} \mathrm{C}$ for $24 \mathrm{~h}$. The B. cereus AR156 cells were pelleted by centrifugation and re-suspended in sterile $10 \mathrm{mM} \mathrm{MgCl}_{2}$ solution and then adjusted density to $5 \times 10^{7} \mathrm{CFU}$ $\mathrm{ml}^{-1}$ for use.
The challenging pathogen Pst DC3000 was cultivated in the liquid King's B medium (peptone $20 \mathrm{~g}, \mathrm{~K}_{2} \mathrm{HPO}_{4} 1.5 \mathrm{~g}$, $\mathrm{MgSO}_{4} .7 \mathrm{H}_{2} \mathrm{O} 1.5 \mathrm{~g}$, Glycerol $10 \mathrm{ml}$, in $1 \mathrm{~L}$ of water), which containing $50 \mathrm{mg} / \mathrm{L}$ of rifampicin at $28^{\circ} \mathrm{C}$ overnight. The Pst DC3000 cells were collected by centrifugation and re-suspended in $10 \mathrm{mM} \mathrm{MgCl}_{2}$ solution, in which containing $0.01 \%(\mathrm{v} / \mathrm{v})$ of the surfactant Silwet L-77 (bought from Sigma, St Louis) and adjusted density to $5 \times 10^{7} \mathrm{CFU} \mathrm{ml}^{-1}$ for use (modified from Niu et al., 2011).

\section{Extraction and Purification of Extracellular Polysaccharides from B. cereus AR156}

The extraction and purification of EPS from B. cereus AR156 cells was carried out by reference to the method of Hung et al. (2005). The B. cereus AR156 cells were inoculated into $1 \mathrm{~L}$ of LB liquid medium within $48 \mathrm{~h}$ after it had been autoclaved at $121^{\circ} \mathrm{C}$ for $20 \mathrm{~min}$. After allowing the culture to grow for $48 \mathrm{~h}$, an aliquot from the bacterial culture was taken and centrifuged at $5000 \mathrm{~g}$ for $30 \mathrm{~min}$. After centrifugation, the culture contained two layers: a pellet and a supernatant. EPS were then extracted from the supernatant. Five volumes of isopropanol were added to precipitate EPS overnight at $4^{\circ} \mathrm{C}$. The next day, the pellets were spun down, re-suspended in $10 \mathrm{ml}$ of freshly made digestion $\operatorname{mix}\left(0.1 \mathrm{M} \mathrm{MgCl}_{2}, 0.1 \mathrm{mg} / \mathrm{ml}\right.$ RNase and $0.1 \mathrm{mg} / \mathrm{ml}$ DNase in $\mathrm{ddH}_{2} \mathrm{O}$ ), and incubated for $1 \mathrm{~h}$ at $37^{\circ} \mathrm{C}$. The treated samples were extracted with equal volumes of phenol:chloroform twice. The samples were then collected and dialyzed in a large volume of $\mathrm{ddH}_{2} \mathrm{O}$ (for example 5L) for $24-48 \mathrm{~h}$ at room temperature. The dialyzed samples were collected and dried using a lyophilizer (LyoQuest $^{\mathrm{TM}}$-85). A $50 \mathrm{mg} / \mathrm{ml}$ EPS aqueous solution was prepared for use in the following experiments (Hung et al., 2005; Dogan et al., 2015).

\section{Hypersensitive Response Analysis}

In this study, we employed two systems to perform a hypersensitive analysis: Arabidopsis and tobacco. In Arabidopsis, the left half of the leaves, which was from 6-weeks-old Arabidopsis plants were infiltrated with $B$. cereus AR156 EPS (50 mg/ml); The Pst DC3000 strains which containing vector only or overexpressing of avrRpt2 $\left(1 \times 10^{7} \mathrm{CFU} \mathrm{ml}{ }^{-1}\right)$, the supernatant of $B$. cereus AR156, and the cell suspension of $B$. cereus AR156 $\left(5 \times 10^{7} \mathrm{CFU} \mathrm{ml}{ }^{-1}\right) \cdot \mathrm{MgCl}_{2}(10 \mathrm{mM})$ and $\mathrm{LB}$ liquid medium were employed as negative controls. Leaves were stained with Trypan Blue 6, 14 or 20 hpi as previously described (Koch and Slusarenko, 1990; Katagiri et al., 2002; Takahashi et al., 2003). The same treatments and methods were used in tobacco. All experiments were performed three times.

\section{Antagonistic Analysis of Extracellular Polysaccharides of $B$. cereus AR156 to Pst DC3000 In Vitro}

In this study, the antagonistic activities of $B$. cereus AR156 EPS and the B. cereus AR156 component were assayed. A $10 \mathrm{~mL}$ suspension of $1.0 \times 10^{7} \mathrm{CFU} / \mathrm{mL}$ Pst DC3000 strains containing vector only or clones expressing avrRpt 2 were added to $1 \mathrm{~L}$ of 
King's B medium (make sure the temperature lower than $50^{\circ} \mathrm{C}$ ), and mixed completely, then poured into plates. A $50 \mathrm{mg} / \mathrm{ml}$ EPS aqueous solution was prepared and added into an Oxford cup; the solution was then placed onto a plate containing previously prepared Pst DC3000 and incubated at $28^{\circ} \mathrm{C}$ for 2 days. This procedure was repeated three times for each treatment. The supernatant of $B$. cereus AR156, LB medium, and sterile water were used as controls. For the B. cereus AR156 itself, the strain was placed onto the plates and incubated at $28^{\circ} \mathrm{C}$ for 2 days. Four repeats were set on one plate. Finally, the diameter of the clear semicircular hyaline zone, which was surrounding the bacterial plaque, was measured after incubation, and the size of the clear semicircular hyaline zone was used to evaluate the antagonistic activities.

\section{Induction Treatments}

Six-weeks-old plants were subjected to bacteria induction treatments in 4 weeks later. For the B. cereus AR156 EPS treatments, $50 \mathrm{mg} / \mathrm{ml}$ EPS was sprayed onto the leaf surface of the Arabidopsis ecotype Col-0 plant. For the control treatment, sterilized water was sprayed onto the leaf surface of the Arabidopsis ecotype Col-0 plant.

Five days after the induction treatment, half of the seedlings in each treatment were challenge-inoculated through spraying the cell suspension of the virulent pathogen Pst DC3000

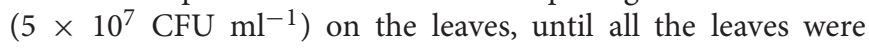
covered with fine droplets. The other halves of the remaining plants were sprayed with $10 \mathrm{mM} \mathrm{MgCl}_{2}$ as the negative control. All the plants were incubated in a dew chamber with $100 \%$ relative humidity for 3 days and then transferred to a normal growth chamber after challenge inoculation.

\section{Density Detection of Pst DC3000 in Arabidopsis Leaves}

To detect the density of Pst DC3000 in Arabidopsis leaves, samples were collected at three time points: 0,3 , and 4 days post inoculation (dpi). Arabidopsis leaves ( $0.1 \mathrm{~g})$ were surface sterilized by $70 \%$ ethanol, then washed in sterilized water for three times, and then homogenized by using a sterilized mortar and pestle with $0.9 \mathrm{ml} 10 \mathrm{mM} \mathrm{MgCl}$. Subsequently, suitable dilutions were plated onto King's B agar containing with $100 \mathrm{mg}$ $\mathrm{1}^{-1}$ cycloheximide and $50 \mathrm{mg} \mathrm{l}^{-1}$ rifampicin (Pieterse et al., 1996), then incubated at $28^{\circ} \mathrm{C}$. After $48 \mathrm{~h}$, the colonies shown on the plate were counted, and then the density of Pst DC3000 in the Arabidopsis leaves was detected, expressed as CFU $\mathrm{g}^{-} 1$ fresh leaf (FW). This experiment was repeated three times. Means were compared by using a LSD test (short of least significant difference) $(P=0.05)$, then the LSD results and standard errors and were calculated (Niu et al., 2011; Jiang et al., 2015).

\section{Detection of Hydrogen Peroxide Accumulation and Activities of SOD and POD}

The content of hydrogen peroxide and the activities of SOD and POD in plants were determined according to the method of Jiang et al. (2015) using a 'Hydrogen Peroxide assay kit', 'SOD detection kit', and 'POD detection kit', respectively, (Nanjing Jiancheng Biological Engineering Institute, Nanjing, China) according to the manufacturer's instructions (Jiang et al., 2015).

To experimental methods used for determining the accumulation of hydrogen peroxide and callose deposition in different treatments were referred from the methods described by Reuber et al. (1998) and Niu et al. (2011). There was no change in our study.

\section{Plant RNA Extraction and RT-PCR Analysis}

Arabidopsis leaves for RT-PCR analysis were soaked in liquid nitrogen. The total RNA of each sample was extracted by the TRIZOL reagent (Invitrogen, Cat. No. 15596-026), referring to the manufacturer's recommendations. RT-PCR was developed with $1 \mathrm{mg}$ total RNA, treated with DNase I (gDNA Wiper from Vazyme ${ }^{\mathrm{TM}}$, Cat. No. R133-01). Reverse transcription was conducted using HiScript ${ }^{\mathrm{TM}}$ Q Select RT SuperMix (Vazyme ${ }^{\mathrm{TM}}$, Cat. No. R133-01). Quantitative RT-PCR was conducted on an ABI 7500 system (ABI) using the SYBR premix Ex-Taq mixture (Takara). PCR was performed under the following conditions: $94^{\circ} \mathrm{C}$ for $5 \mathrm{~min}$, followed by 45 cycles of $94^{\circ} \mathrm{C}$ for $10 \mathrm{~s}, 55^{\circ} \mathrm{C}$ for $20 \mathrm{~s}$, and $72^{\circ} \mathrm{C}$ for $30 \mathrm{~s}$, and end with $72^{\circ} \mathrm{C}$ for $5 \mathrm{~min}$. At-BETATUB 4 (locus: At4g44340) was employed as the internal standard. All the PCR primers used in our study are listed in Supplementary Table S1.

\section{Protein Extraction and Western Blotting Analysis}

To detect the MAPK6 protein expression level during the EPSISR process, samples were collected at 3 and 5 days post-EPS treatment (dpt) and at 6 and $12 \mathrm{~h}$ post Pst DC3000 inoculation (hpi). Arabidopsis leaves were soaked in liquid nitrogen, and the total protein in the leaves was extracted by a homemade protein extraction buffer (Zhang et al., 2011). The protein concentration was detected by using Bradford reagent (Bio$\mathrm{Rad}) .10 \mu \mathrm{g}$ of total protein was size-fractionated by SDS-PAGE gel for Western blotting analysis, then all the proteins were transferred to a Hybond-P PVDF membrane (bought from GE Healthcare) in transfer buffer in which containing 10\% methanol. The membrane was probed with a specific MAPK6 antibody (purchased from Sigma-Aldrich, Cat. No. HPA030262) and a secondary horseradish-peroxide-conjugated antibody (antirabbit-HRP) purchased from Sigma-Aldrich (Cat. No. R2004). The final antibody-protein complexes were determined by using ECL-plus (GE Healthcare) on a Bio-Rad Versa doc 5000, and the image was analyzed using Quantity One software. $\beta$-Tubulin was used as an internal standard. The $\beta$-tubulin antibody was purchased from Sigma-Aldrich (Cat. No. T2200).

\section{Analysis of the Characteristics and Composition of Extracellular Polysaccharide}

Finally, the IR and UV spectra, the molecular weight and the monosaccharide composition of the sample were obtained to analyze the characteristics and composition of B. cereus 
AR156 EPS. The IR spectrum analysis was carried out by using an FTIR, Jasco 6100, Model Japan (resolution: $4 \mathrm{~cm}^{-1}$ ). The sample was ground with spectroscopic grade potassium bromide powder and then pressed into a $1 \mathrm{~mm}$ pellet for FTIR measurement over the frequency range of 4000$400 \mathrm{~cm}^{-1}$ (Mid infrared region). The UV spectrum of the EPS was recorded by using a T80+UV/VIS Spectrometer, PG Instrument Ltd. (range: 190-1000 nm). The molecular weight and monosaccharide composition assays were performed as described by Haroun and associates (Haroun et al., 2013).

\section{Statistical Analysis}

All bioassays were conducted three times with 24 seedlings per treatment. Analysis of variance (ANOVA) was carried out using SPSS software version 19.0 (IBM). A mean comparison was conducted by using LSD test $(P<0.05)$. Standard errors and standard deviations (SDs) were calculated.

\section{RESULTS}

\section{The Extracellular Polysaccharides of B. cereus AR156 Elicited Strong HR in Plants Leaves}

In our previous study, B. cereus AR156 was found to not only promote the growth of Arabidopsis but also trigger ISR (Niu et al., 2011). To demonstrate how B. cereus AR156 was perceived by plants and how ISR was triggered in plants, a series of components of $B$. cereus AR156 were examined and tested in this study. As shown in Figure 1, the Arabidopsis leaves of the B. cereus AR156 EPS treatment started to show HR symptoms $6 \mathrm{~h}$ post infiltration (hpi), and the symptoms became more significant at $12 \mathrm{~h}$ (Figure 1). The same symptoms were observed in B. cereus AR156 and its supernatant treatment. In this study, we also used Pst DC3000 strains containing vector only or clones expressing avrRpt2 as a control. The results described in a previous study are shown in Figure 1(Takahashi et al., 2003). To confirm these results, we employed a tobacco system to repeat the experiments. As shown in Figure S1, the $B$. cereus AR156 EPS could significantly elicit HR on tobacco leaves (Supplementary Figure $\mathrm{S} 1$ ). The $B$. cereus AR156 could trigger $\mathrm{HR}$ on non-host plants in a manner resembling that observed for the pathogenic $P$. syringae strain Pst DC3000. B. cereus AR156 is avirulent to plants such as Arabidopsis (data not shown). Therefore, we concluded that $B$. cereus AR156 might act as a beneficial elicitor that could be perceived by plants and could trigger immunity similarly to pathogens.

\section{The Extracellular Polysaccharides of B. cereus AR156 Triggered ISR to Pst DC3000 in Arabidopsis}

Research has shown that flg22 can induce ROS production and enhance plant resistance to Pst DC3000 infection (Lu et al.,
2009; Zhang et al., 2010; Lin et al., 2014). To determine whether B. cereus AR156 EPS 6 could act as a MAMPs and induce systemic resistance to Pst DC3000 infection, B. cereus AR156 EPS were analyzed for their ability to trigger ISR to Pst DC3000 in Arabidopsis Col-0 plants in a greenhouse trial, in which $\mathrm{H}_{2} \mathrm{O}$ was employed as a mock treatment. Four dpi, typical symptoms of bacterial speck disease-water-soaked spots or yellowing leaves or surrounded by extensive chlorosis was shown on the surface of the mock-treated plants leaves (Figures 2A,B). Moreover, compared with the controls, the pretreatment with $B$. cereus AR156 EPS caused a significant $(P<0.05)$ decrease in disease severity in Arabidopsis Col-0 plants (Figure 2C); therefore, the biocontrol efficacy of $B$. cereus AR156 in reducing the leaf speck disease caused by Pst DC3000 could up to $62.71 \%$ (Supplementary Table S2). To prove that the abovementioned result was not caused by the antagonistic effect of $B$. cereus AR156 EPS on Pst DC3000 in Arabidopsis Col-0 plants, we carried out an evaluation experiment on the antagonism of B. cereus AR156 and Pst DC3000 in vitro. As shown in Supplementary Figure S2, B. cereus AR156 EPS had no antagonistic effect on Pst DC3000. Overall, we could conclude that the $B$. cereus AR156 EPS could induce systemic resistance to Pst DC3000 in Arabidopsis Col-0 plants.

\section{The Extracellular Polysaccharides of B. cereus AR156 Induced Defense-related Gene Expression in Arabidopsis}

Enhanced disease resistance in Arabidopsis is often accompanied by enhanced transcription of $P R$ genes (such as $P R 1, P R 2$, and PR5) associated with the SA-mediated defense signaling pathway (Uknes et al., 1992; Jiang et al., 2015) and the PDF1.2 gene associated with the JA/ET- mediated defense pathway. To test whether B. cereus AR156 EPS could induce expression levels of defense-related genes, the expression levels of all four genes were examined in plants, which were treated with B. cereus AR156 EPS and Pst DC3000 inoculation. As demonstrated in Figure 3, compared with the mock treatment, the transcripts of three $P R$ genes were accumulated to a higher degree in the leaves treated with $B$. cereus AR156 EPS from 1 to $5 \mathrm{dpi}$ and reached their maximums at $3 \mathrm{dpi}$ (Figures $\mathbf{3 A}, \mathbf{C}, \mathbf{E}$ ); however, there was no significant change in the expression level of PDF1.2 gene (Figure 3G).

Q-RT-PCR was also employed to analyze the transcription of the four genes in Arabidopsis ecotype Col-0 plants, which were inoculated with Pst DC3000 alone and in those treated with B. cereus AR156 EPS and inoculated with Pst DC3000. During the pathogen challenging process, Q-RT-PCR revealed that $B$. cereus AR156 EPS stimulated the transcription of PR1, PR2, and PR5 in Arabidopsis ecotype Col-0, which reached their maximums at $6 \mathrm{hpi}$ in the samples treated with B. cereus AR156 EPS and inoculated with Pst DC3000 (Figures 3B,D,F). Regarding the expression levels of PDF1.2 genes, there was no significant difference between the $B$. cereus AR156 EPS treatment and the mock treatment (Figure 3H). 


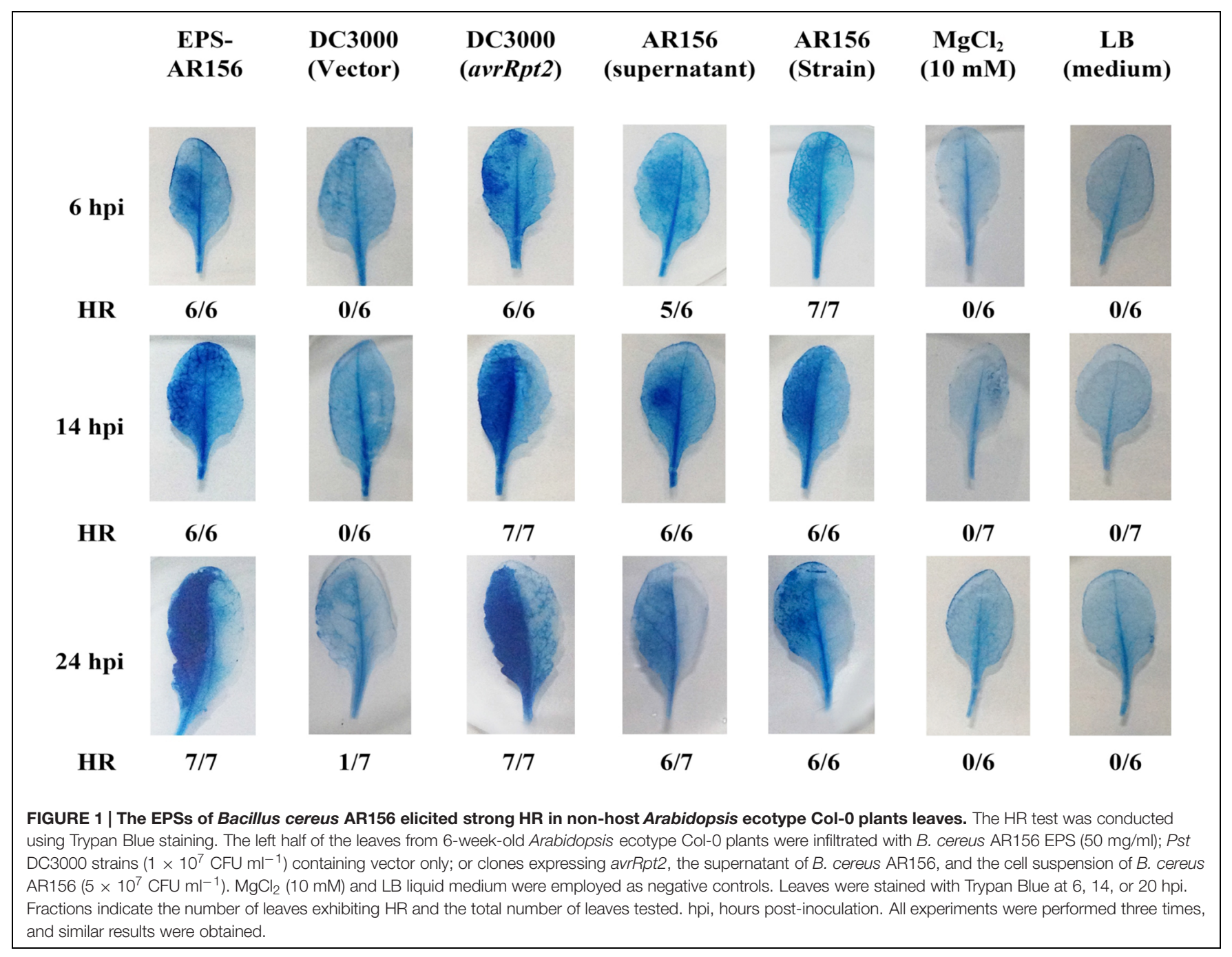

These results indicated that the transcription of the three $P R$ genes (PR1, PR2, and PR5) in Arabidopsis treated with B. cereus AR156 EPS and inoculated with Pst DC3000 was more rapid than the treatment inoculated with Pst DC3000 alone. Furthermore, over all test periods, transcription of three $P R$ genes (PR1, PR2, and PR5) was stronger in Arabidopsis treated with $B$. cereus AR156 EPS and inoculated with Pst DC3000 than that in Arabidopsis inoculated with Pst DC3000 alone.

\section{The Extracellular Polysaccharides of B. cereus AR156 Primes for Hydrogen Peroxide Accumulation, Callose Deposition, and Increased Defense-related Enzyme Activities in Arabidopsis}

In plants, rhizobacteria-trigered ISR is usually combined with the enhancement of activity of cellular defense responses, such as a hydrogen peroxide rapidly accumulation, callose deposition and increased defense-related enzyme activities (Conrath et al., 2002;
Van Wees et al., 2008), which are response upon the pathogen attack. B. cereus AR156 has been demonstrated to be able to prime Arabidopsis for potentiated cellular defense responses (Niu et al., 2011; Jiang et al., 2015). To examine whether B. cereus AR156 EPS could enhance the activities of the cellular defense responses, hydrogen peroxide accumulation, callose deposition and defense-related enzyme activities in Arabidopsis ecotype Col0 were detected. As shown in Supplementary Figure S3 and Figure 4A, under the conditions without pathogen challenge, the accumulation of hydrogen peroxide and callose were determined at $3 \mathrm{dpi}$ in the leaves of Arabisopsis pre-treated with B. cereus AR156 EPS. At $5 \mathrm{dpi}$, the change in cellular defense responses tended to decrease and stabilize, and as shown in Figure $\mathbf{4 A}$, hydrogen peroxide accumulation peaked at $3 \mathrm{dpi}$ in the leaves of Arabidopsis ecotype Col-0 plants treated with B. cereus AR156 EPS. These results are in agreement with those previously obtained from histone staining (Ref). Regarding its effect on defense-related enzyme activities, the B. cereus AR156 EPS treatment led to potentiated SOD and POD activities in the leaves of Arabidopsis ecotype Col-0 plants not challenged with Pst DC3000 at $3 \mathrm{dpt}$ compared with the mock treatment. Under 
A

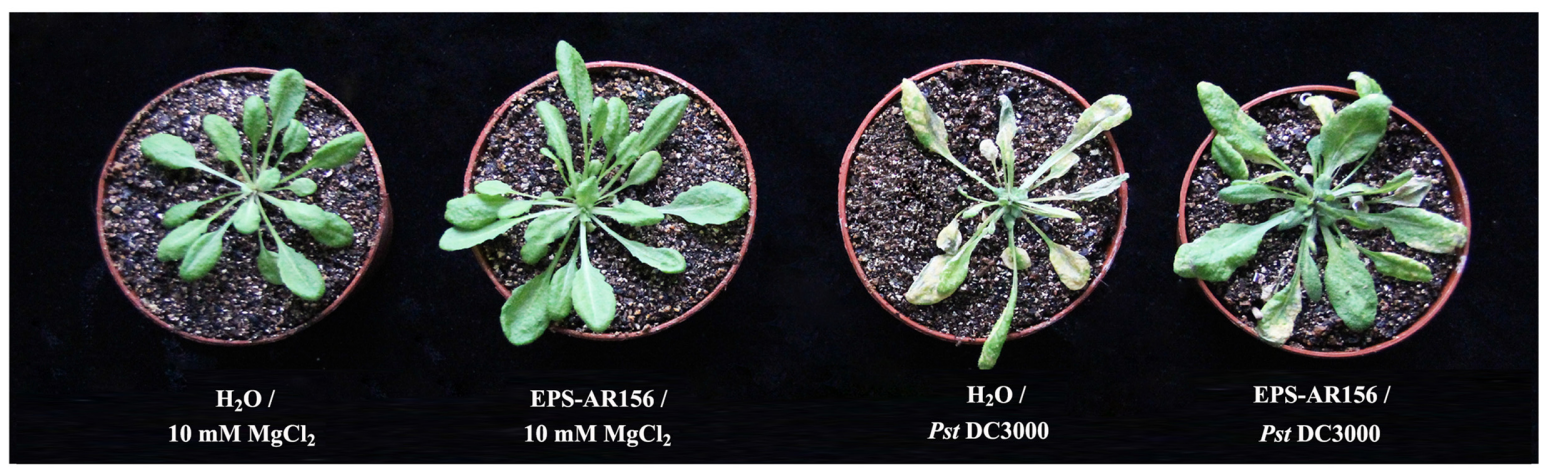

B

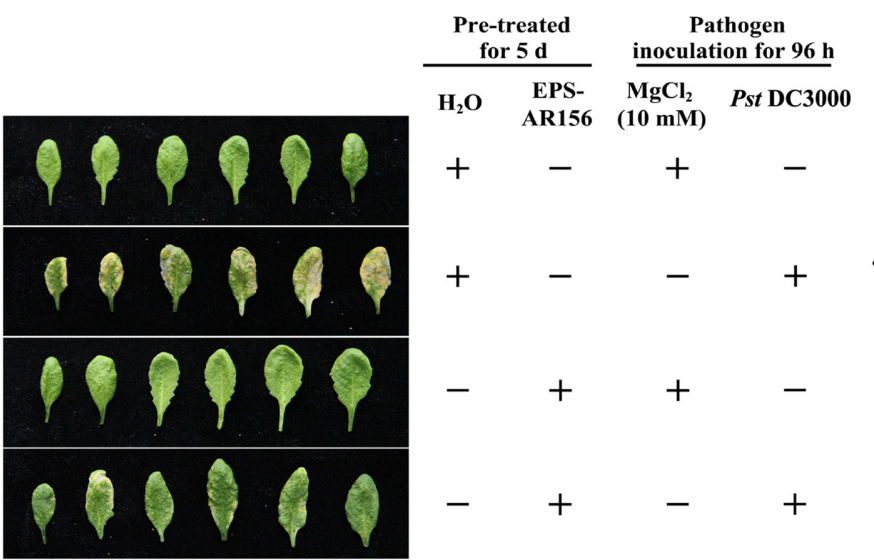

C

Pathogen density in the Arabidopsis leaves

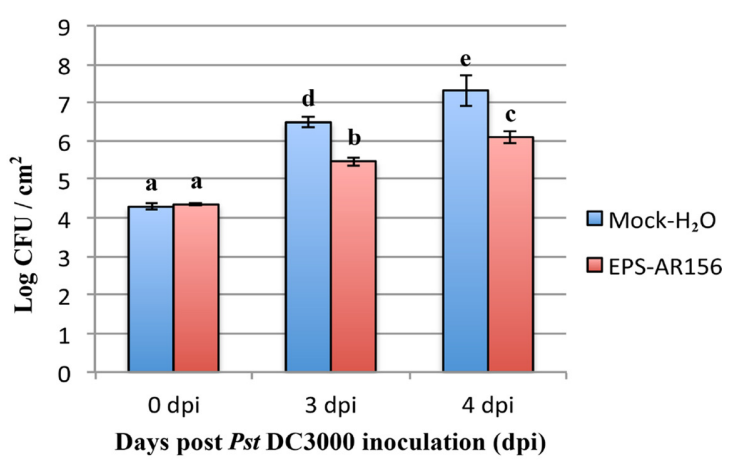

FIGURE 2 | Induction of resistance to Pst DC3000 by the EPSs of B. cereus AR156 in Arabidopsis ecotype Col-0 plants. Plants were pretreated by being sprayed with B. cereus AR156 EPS ( $50 \mathrm{mg} / \mathrm{ml}$ ) or sterile water (as a mock control). Five days later, leaves were sprayed with Pst DC3000 at $5 \times 10^{7} \mathrm{CFU} \mathrm{ml}^{-1}$ or $10 \mathrm{mM} \mathrm{MgCl}_{2}$ (as a mock control). (A,B) Disease symptoms caused by Pst DC3000 infection in Arabidopsis plants. A representative plant from each treatment was photographed at 5 dpi. (C) Bacterial growth assay of Pst DC3000 in Arabidopsis treated with B. cereus AR156 EPS or sterile water. Data are means and standard deviations (SDs) $(n=24)$. Letters above the bars indicate statistically significant differences between treatments [least significant difference (LSD) test, $P<0.05]$. dpt, days post-inoculation. All experiments were performed three times, and similar results were obtained.

the conditions without pathogen challenge, the B. cereus AR156 EPS treatment increased the activities of SOD and POD at 1 and $3 \mathrm{dpt}$, respectively (Figures 4C,E). With pathogen challenging, he accumulation of hydrogen peroxide and callose were obviously determined at $12 \mathrm{hpi}$ in the leaves of Arabidopsis pre-treated with B. cereus AR156 EPS and inoculated with Pst DC3000, whereas these defense responses were observed at 24 hpi in plants inoculated with Pst DC3000 alone (Figure 5). As shown in Figure 4B, in the leaves of Arabidopsis ecotype Col-0 plants, which was treated with $B$. cereus AR156 EPS and inoculated with Pst DC3000, hydrogen peroxide accumulation reached a maximum at $6 \mathrm{hpi}$; however, in the leaves of plants inoculated with Pst DC3000 alone, hydrogen accumulation reached a maximum at $24 \mathrm{hpi}$. These results are in agreement with those previously obtained by histone staining. Regarding its effect on defense-related enzyme activities, the $B$. cereus AR156 EPS treatment elevated the activities of SOD and POD at 3 and $12 \mathrm{hpi}$, respectively, (Figures 5D,F). These results indicate that the B. cereus AR156 EPS pre-treatment could make plants respond to pathogen infestation faster and more strongly by enhancing the activation of cellular defense responses.

\section{SA Signaling Pathways and NPR1 are Involved in the Extracellular Polysaccharides of B. cereus AR156 Induced Systemic Resistance in Arabidopsis}

To identify the signal transduction pathways involved in B. cereus AR156 EPS ISR in Arabidopsis, an epistasis analysis method was used. We compared the levels of B. cereus AR156 EPS-induced resistance to Pst DC3000 in the wild-ecotype Arabidopsis Col0, some Arabidopsis mutants asscociated with defense-signaling pathways, jarl, etr1, and nprland the transgenic line NahG, and. Pre-treated with $B$. cereus AR156 EPS caused a significant $(P<0.05)$ reduction in disease severity in all tested Arabidopsis lines except for NahG and nprl compared with the respective controls inoculated with only Pst DC3000 (Figure 6).

At 3 and 4 dpi, pretreatment with $B$. cereus AR156 EPS led to a significant $(P<0.05)$ reduction in density of pathogen $P s t$ DC3000 in the leaves of all tested Arabidopsis lines except for NahG and npr 1 compared with the respective controls inoculated with only Pst DC3000, indicating that the induction of ISR by 
A

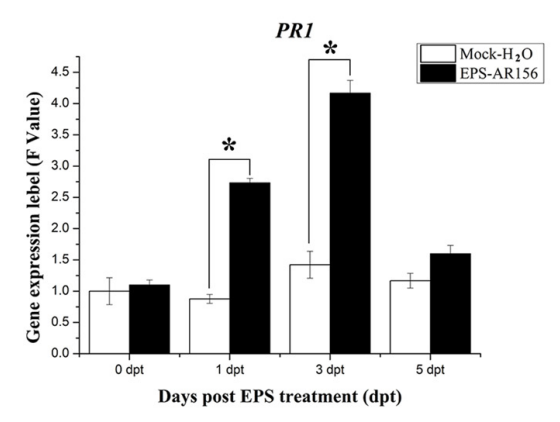

C

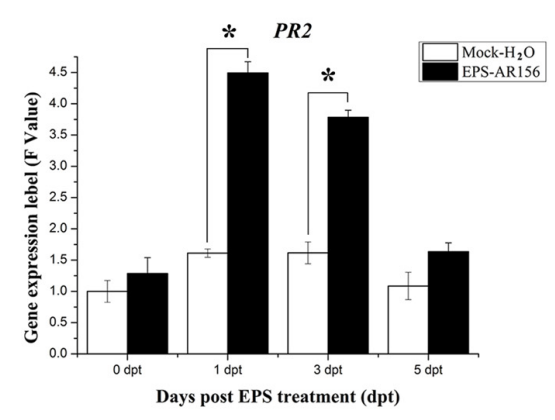

E

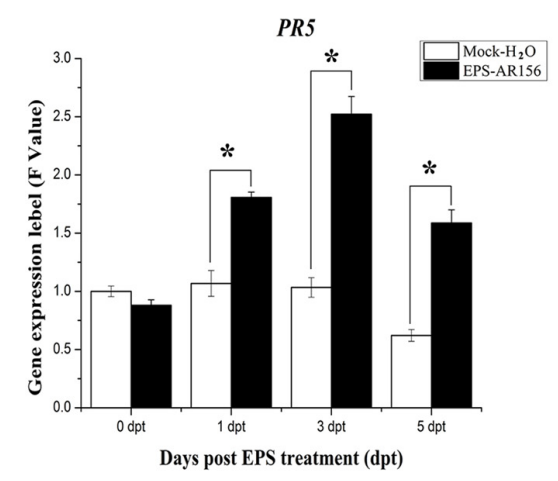

G

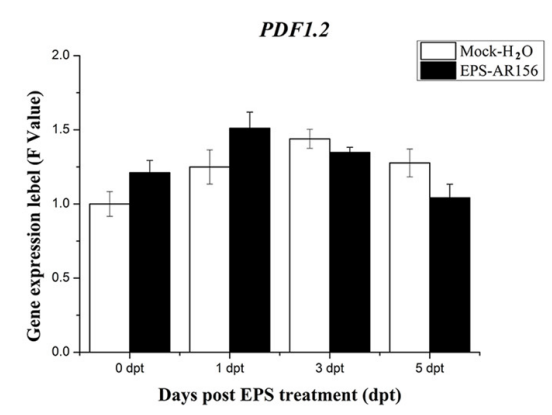

B

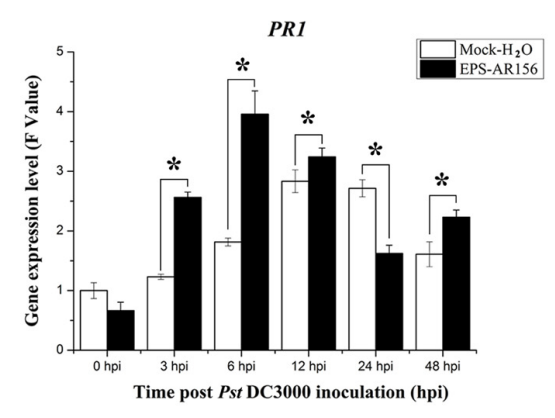

D

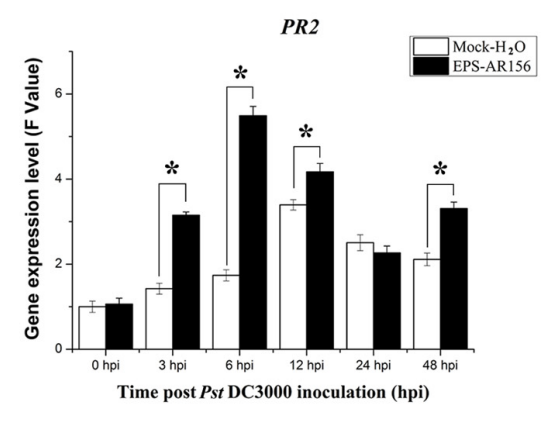

F

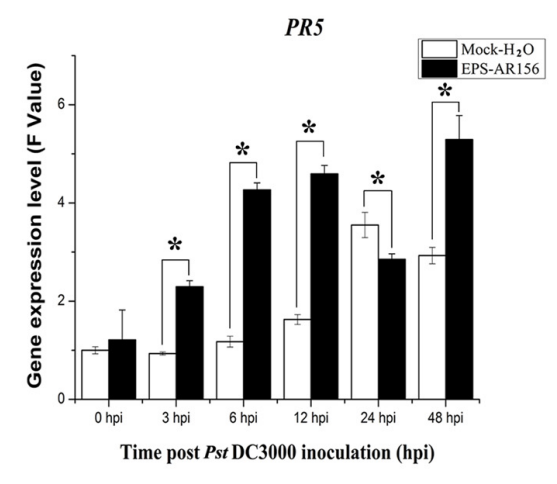

H

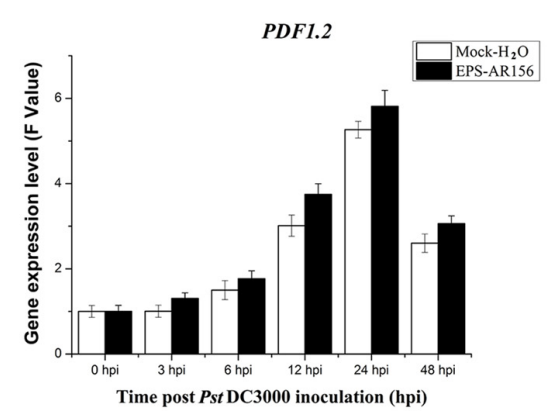

FIGURE 3 | Differential expression of SA and JA/ET signal markers in Arabidopsis ecotype Col-0. Leaves of Arabidopsis ecotype Col-0 were harvested at the indicated time points for extracting total RNA. Gene expression levels were determined by Q-RT-PCR. (A-H) Time course of expression of PR1, PR2, PR5, and PDF1.2 genes in the leaves of Arabidopsis ecotype Col-0 treated with B. cereus AR156 EPS alone and EPS-pretreated plants inoculated with Pst DC3000. The expression values of the individual genes were normalized using $\beta$-tubulin 4 as an internal standard. Data represent the average values of at least three biological replicates, each repeated in duplicate in the same run, and SDs $\left({ }^{*} P<0.05\right)$. dpt, days post-treatment with EPS; hpi, hours post-inoculation with $P$ st DC3000. All experiments were performed three times, and similar results were obtained. 


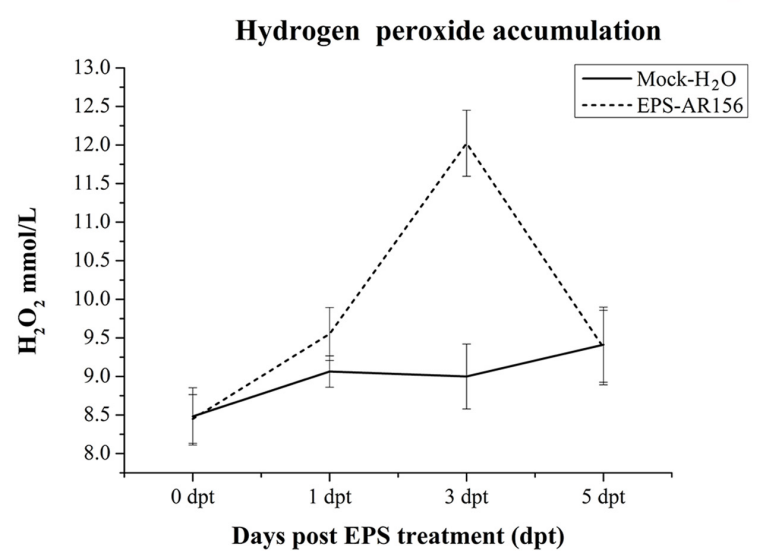

C

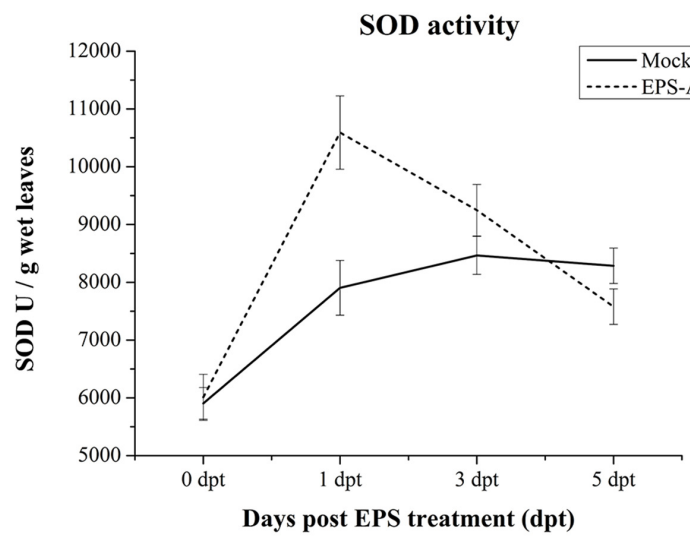

E

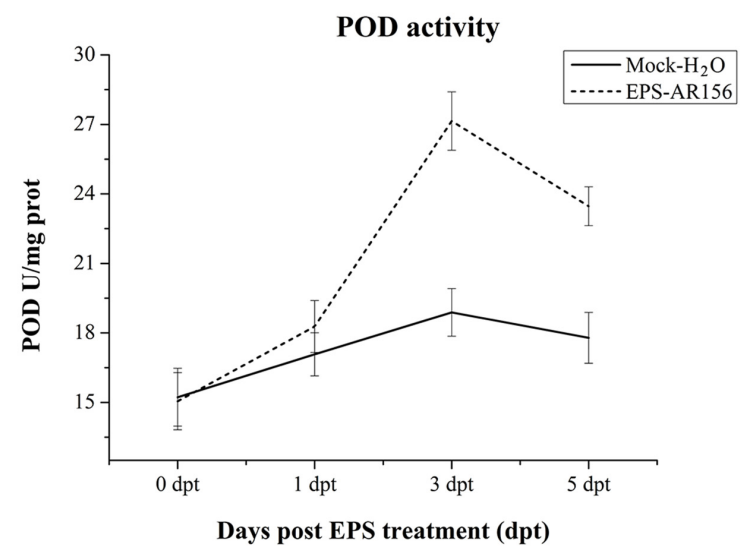

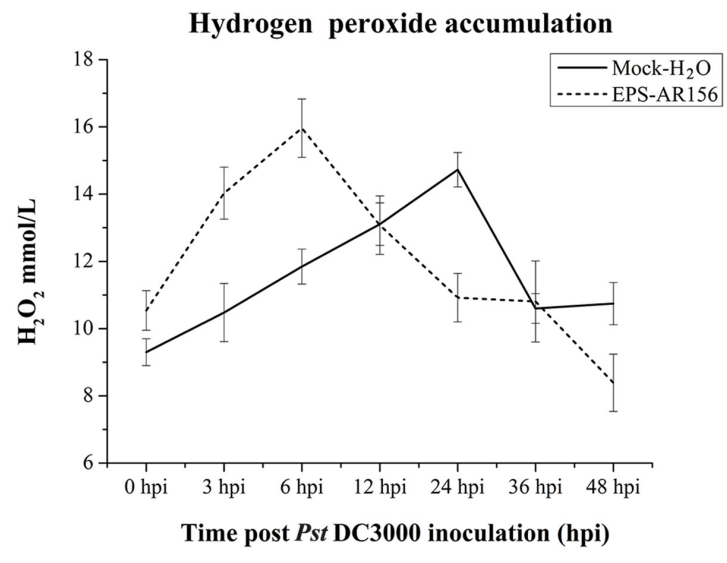

D

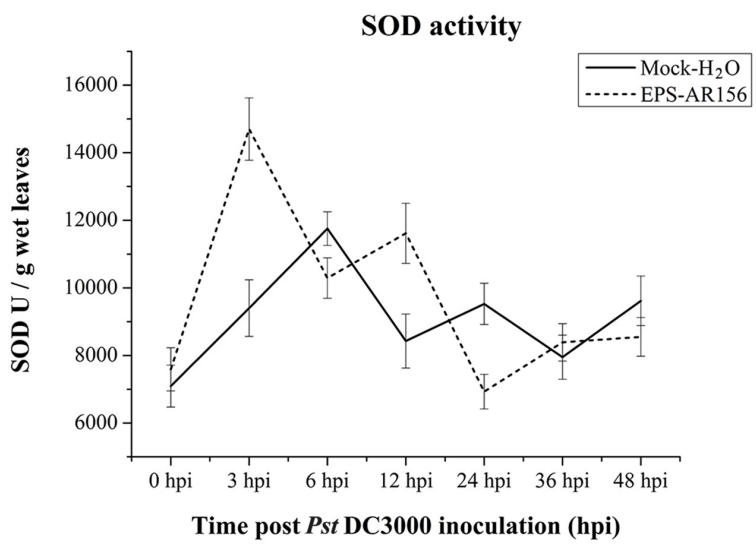

$\mathbf{F}$

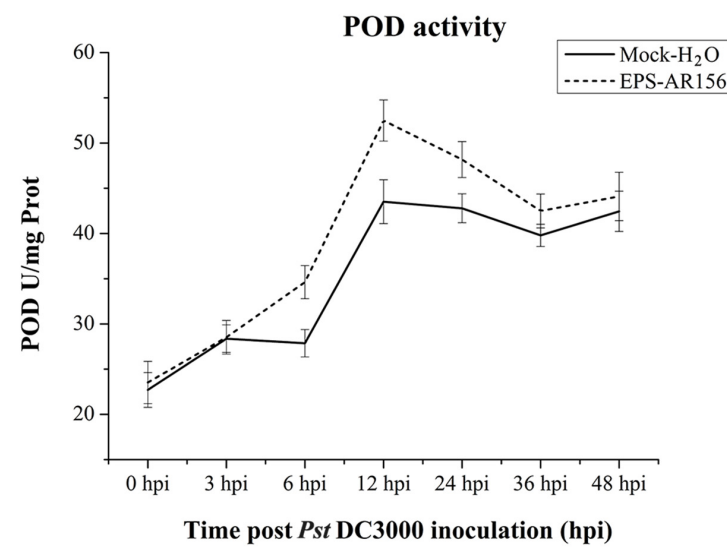

FIGURE 4 | Effect of the EPSs of B. cereus AR156 and pathogen challenge on hydrogen peroxide accumulation and defense-related enzyme activities in the defense responses of Arabidopsis ecotype Col-0. Leaves of Arabidopsis ecotype Col-0 were harvested at the indicated time points for the evaluation of hydrogen peroxide accumulation and defense-related enzyme activity. (A,B) Time course of hydrogen peroxide accumulation; (C,D) SOD activity of defense-related enzymes; and (E,F) POD activity in the leaves of Arabidopsis ecotype Col-0 treated with B. cereus AR156 EPS for 5 days and inoculated with Pst DC3000. Error bars represent the standard errors of four independent treatment samples; dpt, days post-treatment; hpi, hours post-inoculation. All experiments were performed three times, and similar results were obtained. 


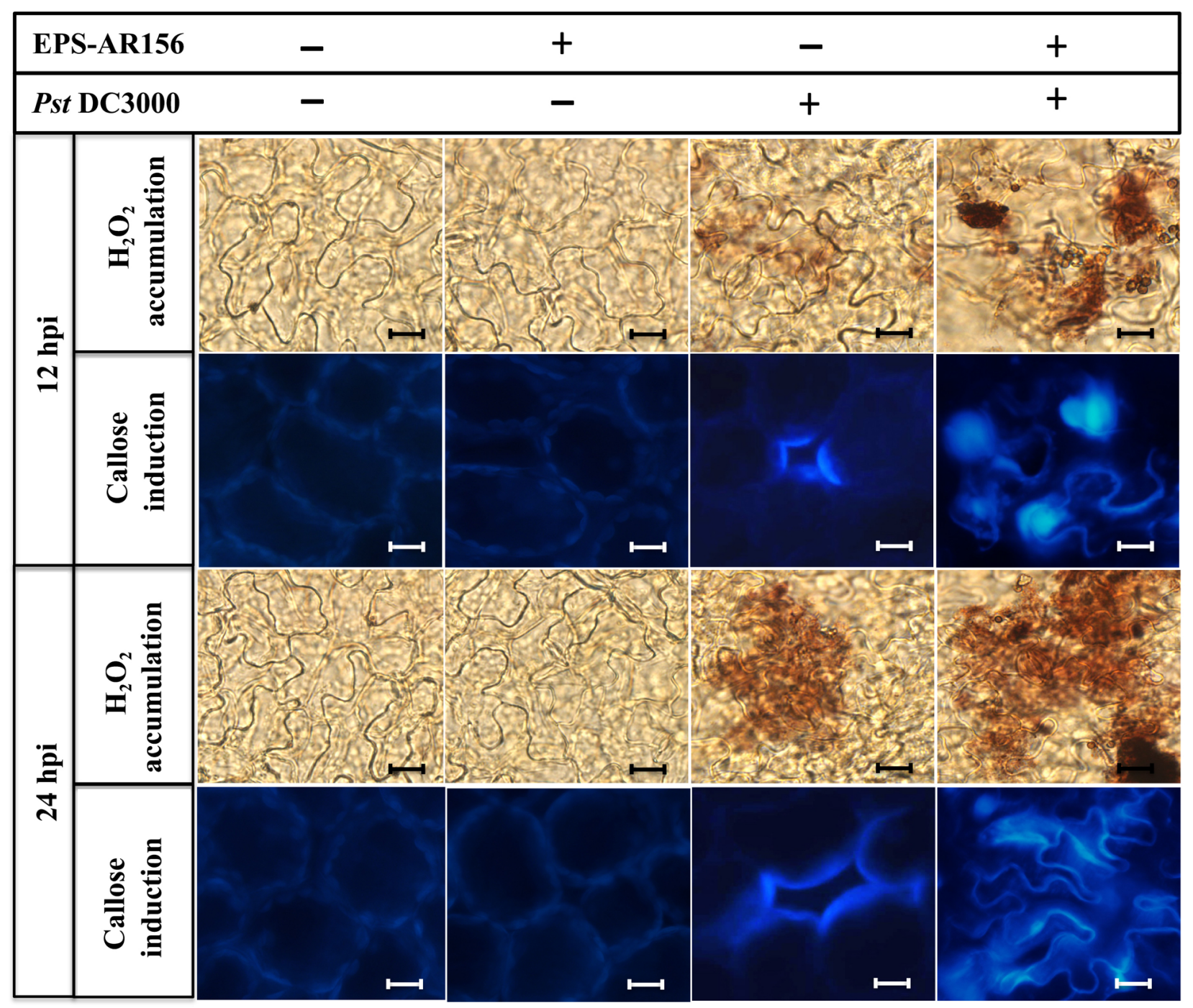

FIGURE 5 | The EPSs of B. cereus AR156 induced hydrogen peroxide accumulation and callose deposition in the leaves of Arabidopsis ecotype Col-0 plants upon Pst DC3000 attack. Arabidopsis ecotype Col-0 plants were inoculated with Pst DC3000 5 days after the B. cereus AR156 EPS or sterile water treatment, and the leaves were sampled at 12 and $24 \mathrm{hpi}$. Hydrogen peroxide accumulation and callose deposition were observed under light and epifluorescence microscopes, respectively. Scale bars represent $20 \mu \mathrm{m}$. hpi, hours post-inoculation. All experiments were performed three times, and similar results were obtained.

B. cereus AR156 EPS occurred through the SA signaling pathway and was NPR1-dependent in Arabidopsis (Figure 6). These results are in agreement with those previously observed in defenserelated gene expression detection components and also provide a reasonable explanation why $B$. cereus AR156 EPS could affect the transcription level of SA signaling pathway marker genes $(P R 1$, $P R 2$, and $P R 5)$, rather than that of the JA-responsive marker gene PDF1.2.

\section{The Extracellular Polysaccharides of B. cereus AR156 Trigger ISR through MAPK Signaling Pathway}

Microbe-associated molecular patterns or PAMPs must be perceived by PRRs (plasma-membrane localized PRRs) combined with the motivated of MAPK and trigger plant immunity (Trdá et al., 2015). For example, pathogen infection or treatments with bacterial flagellin-derived flg22 peptide, which was know as a conserved PAMP, can enhance the activation of the four Arabidopsis MAPKs: MPK4, MPK3, MPK6, and MPK11 (Asai et al., 2002; Beckers et al., 2009; Bethke et al., 2011). To clarify whether $B$. cereus AR156 EPS could be MAMPs and activate MAPK to trigger plant immunity, we detected the expression level of one type of Arabidopsis MAPK-MPK6, which is known to be activated by MAMPs-during the process of B. cereus AR156 EPS-ISR to Pst DC3000. As shown in Figure 7, Q-RT-PCR revealed that MPK6 showed significantly altered expression levels in the $B$. cereus AR156 EPS-treated plants compared with the mock-treated ones and reached a maximum at $1 \mathrm{dpt}$ (Figure 7A). During the pathogen challenging process, 


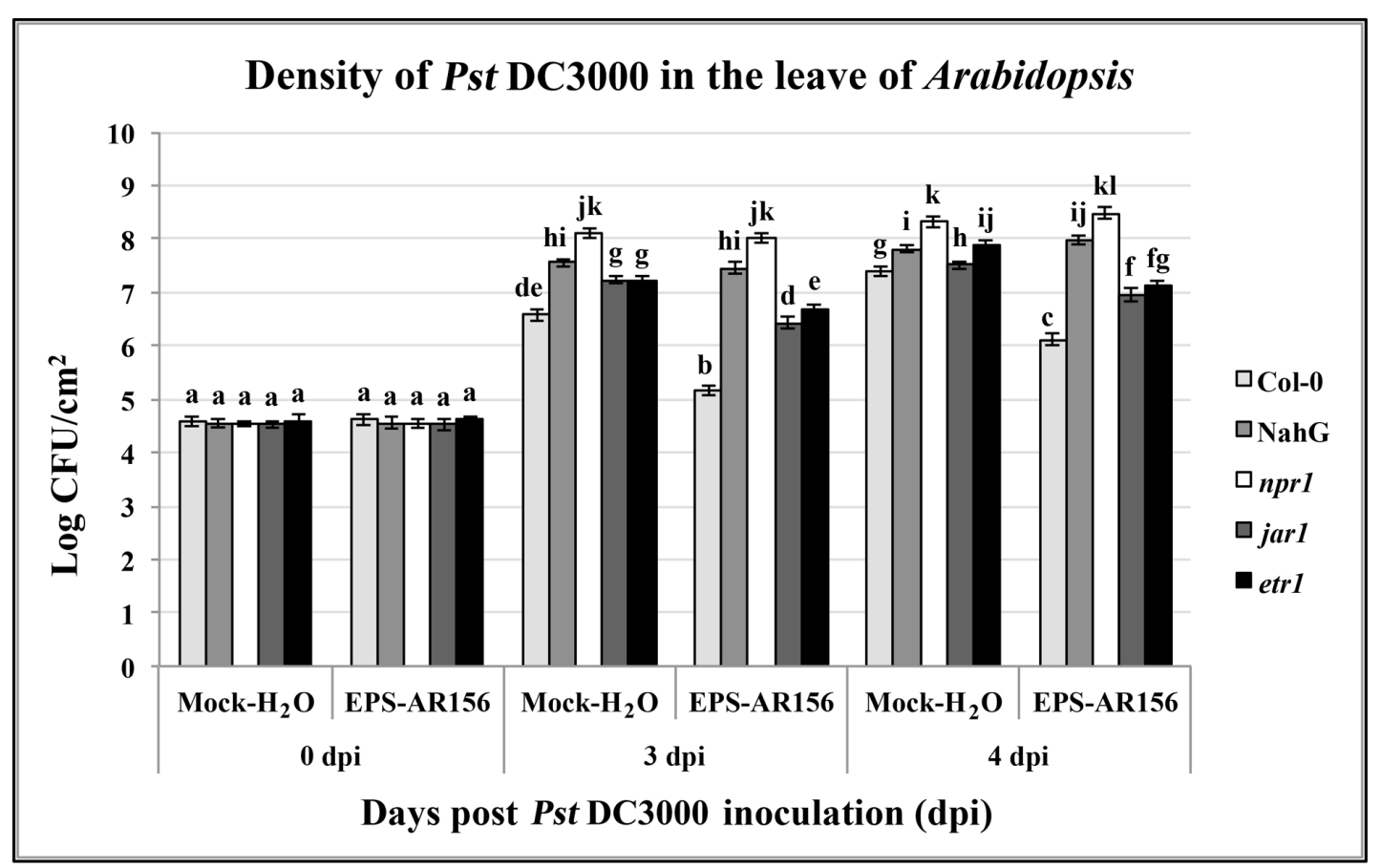

FIGURE 6 | The EPSs of B. cereus AR156-mediated induced systemic resistance to Pst DC3000 in Arabidopsis Col-0, NahG, etr1, jar1, and npr1 plants at phenotypic. Density of Pst DC3000 in the leaves of Arabidopsis plants were measured. Plants were inoculated with Pst DC3000 at 5 days post-treatment with B. cereus AR156 EPS (dpt), and leaves were harvested at 0, 3, 4, days post-inoculation. Bars represent average number of CFU per gram of leaf fresh weight. Data are means and SDs $(n=24)$. Letters above the bars indicate statistically significant differences between treatments [least significant difference $($ LSD) test, $P<0.05]$. All experiments were performed three times, and similar results were obtained.

Q-RT-PCR revealed that B. cereus AR156 EPS stimulated the transcription of MPK6 in Arabidopsis ecotype Col-0 and reached the maximum levels at $6 \mathrm{hpi}$ in the Arabidopsis plants, which was treated with B. cereus AR156 EPS and inoculated with Pst DC3000 (Figure 7B). Moreover, the expression level of MPK6 was also detected by Western blotting with a commercial MPK6 antibody, and the results were consistent with the detection of MPK6 in Arabidopsis ecotype Col-0 by Q-RT-PCR. As shown in Figures 7C,D, B. cereus AR156 EPS could enhance the expression level of MPK6 at $1 \mathrm{dpt}$, and in the leaves of Arabidopsis ecotype Col-0, which was treated with $B$. cereus AR156 EPS and inoculated with Pst DC3000, the expression level of MPK6 reached a maximum at $6 \mathrm{hpi}$ (Figure 7C); however, in the leaves of plants inoculated with Pst DC3000 alone, the expression level of MPK6 reached a maximum at $12 \mathrm{hpi}$ (Figure 7C). These results suggest that $B$. cereus AR156 EPS could be MAMPs and trigger ISR through MAPK signaling as well, and the activation of MAPK signaling in plants, pre-treated with B. cereus AR156 EPS and inoculated with Pst DC3000 show more faster and rapid than that in plants inoculated with Pst DC3000 alone.

\section{Characteristics and Composition Analysis of Extracellular Polysaccharide} of $B$. cereus AR156

Investigations of the chemical compositions and molecular structures of EPS are important for establishing their function relationship. Therefore, in this study, we also analyzed the characteristics and composition of EPS extracted from $B$. cereus AR156, which could act as a MAMPs. As shown in Supplementary Figure S4, the UV scanning curve of B. cereus AR156 EPS was smooth, with a single peak at $196 \mathrm{~nm}$ and no absorption peak at 260 and $280 \mathrm{~nm}$, suggesting that were no protein, polypeptide or nucleic acid components in the EPS samples. The IR spectral analysis results show that the EPS molecules contained different functional groups, such as hydroxyl, alkane, and carbonyl groups (Supplementary Figure S5). We also demonstrated that the average molecular weight of $B$. cereus AR156 EPS was approximately $13272 \mathrm{Da}$, as shown in Supplementary Figure S6.

After hydrolysis and anthranilic acid derivatization, the sugar composition of $B$. cereus AR156 EPS was analyzed by HPLC. The monosaccharide composition of EPS was found to consist of mannose, galactose and glucose (Supplementary Figures S7A,B). In terms of weight, mannose $(70.97 \%)$ was found to be the major monosaccharide, followed by galactose (17.59\%) and glucose (11.45\%) (Supplementary Figure S7B).

\section{DISCUSSION}

In recent years, series of studies have established the functions of beneficial plant growth promotion rhizobacteria (PGPRs) on improving plant health by increasing resistance to insect pests, 


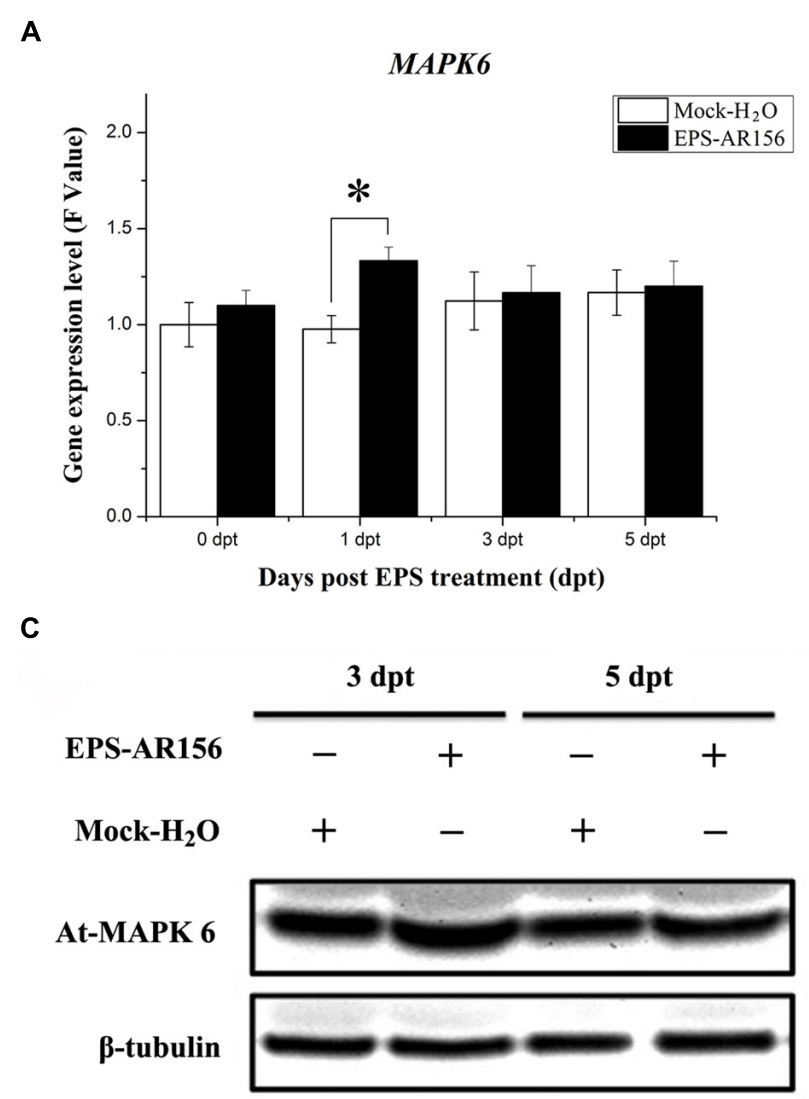

B

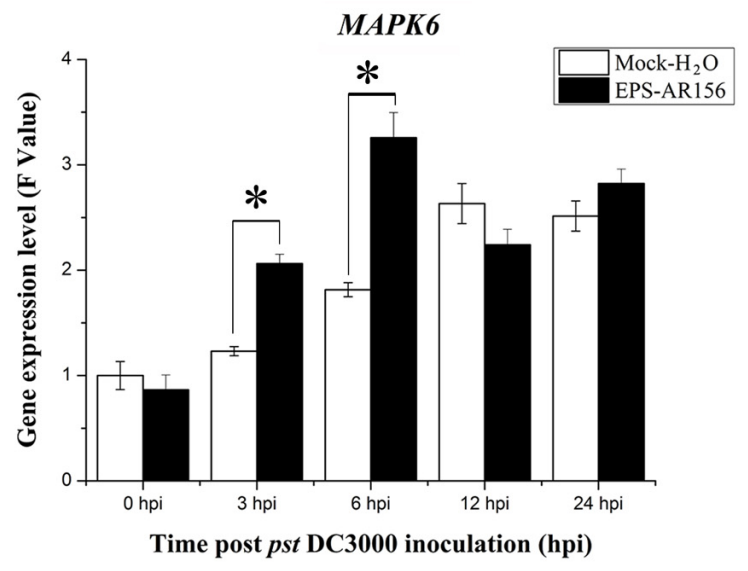

D

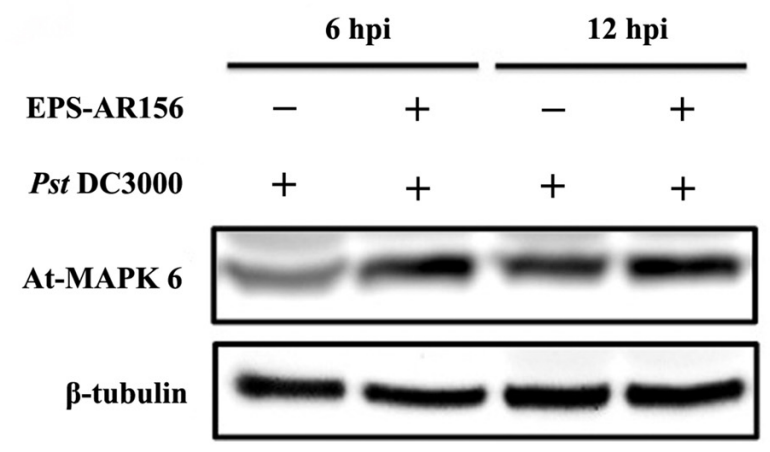

FIGURE 7 | The EPSs of B. cereus AR156 induced MAPK6 expression in the leaves of Arabidopsis ecotype Col-0 plants upon Pst DC3000 attack. Leaves of Arabidopsis ecotype Col-0 treated with B. cereus AR156 EPS alone and EPS-pretreated plants inoculated with Pst DC3000 were harvested at the indicated time points to extract total RNA and protein; (A,B) MAPK6 gene expression levels were determined by Q-RT-PCR. The expression values of the individual genes were normalized using $\beta$-tubulin 4 as an internal standard. Data represent the average values of at least three biological replicates, each repeated in duplicate in the same run, and SDs (*P < 0.05). (C,D) Expression of MAPK6 in the Arabidopsis ecotype Col-0 treated with B. cereus AR156 EPS alone and EPS-pretreated plants inoculated with Pst DC3000 by Western blotting with a commercial MAPK6 antibody (Sigma-Aldrich), $\beta$-Tubulin was used as an internal standard. The $\beta$-tubulin antibody was purchased from Sigma-Aldrich. All experiments were performed three times, and similar results were obtained.

pathogens, and abiotic stressors, such as salinity and drought (Zhang et al., 2008, 2010; Lakshmanan et al., 2012). Among these PGPR strains, B. cereus AR156 could reduce disease severity when rhizoinoculated onto the roots of Arabidopsis plants. Niu et al. (2011) reported that AR156 inhibit the proliferation of the foliar pathogen Pst DC3000 through ISR, which was dependent on NPR1 and involved both the SA and JA/ET two signaling pathways. The two transcriptional factors WRKY11 and WRKY70 play roles in B. cereus AR156-triggered ISR to Pst DC3000, which explains why B. cereus AR156 could trigger ISR through the simultaneous activation of the SA and JA/ET two signaling pathways (Jiang et al., 2015). However, little was know on how the plant roots perceive the colonization of rhizobacteria, such as $B$. cereus AR156, and trigger ISR in response to pathogen attack. In this study, we demonstrated that the B. cereus AR156 EPS could act as novel MAMPs, be recognized by plants, and then trigger immunity to Pst DC3000 in Arabidopsis. We also found that perception and ISR triggering occurred through MAPK signaling and SA-signaling pathways and was NPR1dependent.
Arabidopsis response to Pst DC3000 is ordinarily related to concomitant activation of the JA/ET defense signaling (Van Loon et al., 1998). As the results shown, the B. cereus AR156 EPS did not enhance the expression level of the JA/ET marker gene PDF1.2 (Figures 3G,H), and pre-treatment with B. cereus AR156 EPS could significantly $(P<0.05)$ reduced the disease severity in jarl and etr1 mutants (Figure 6), all these indicated that the JA/ET-dependent defense responses were not potentiated by B. cereus AR156 EPS upon Pst DC3000 infection. By contrast, B. cereus AR156 EPS primed the expression level of the SA-responsive genes (PR1, PR2, and PR5) upon Pst DC3000 invasion (Figures 3A-F), indicating that SA signaling might be responsible for B. cereus AR156 EPS-induced Arabidopsis resistance to Pst DC3000. Different bacterial PAMPs, containing flg22, could induce overlapping genes (Zipfel et al., 2004), and some studies have shown that flg22-induced gene regulation and expression are shown SA-dependent after flg22 administration (Vlot et al., 2009). In our study, we also found that the B. cereus AR156 EPS, by acting as novel MAMPs, could induce systemic resistance to Pst DC3000 by activating the SA signaling pathway, 


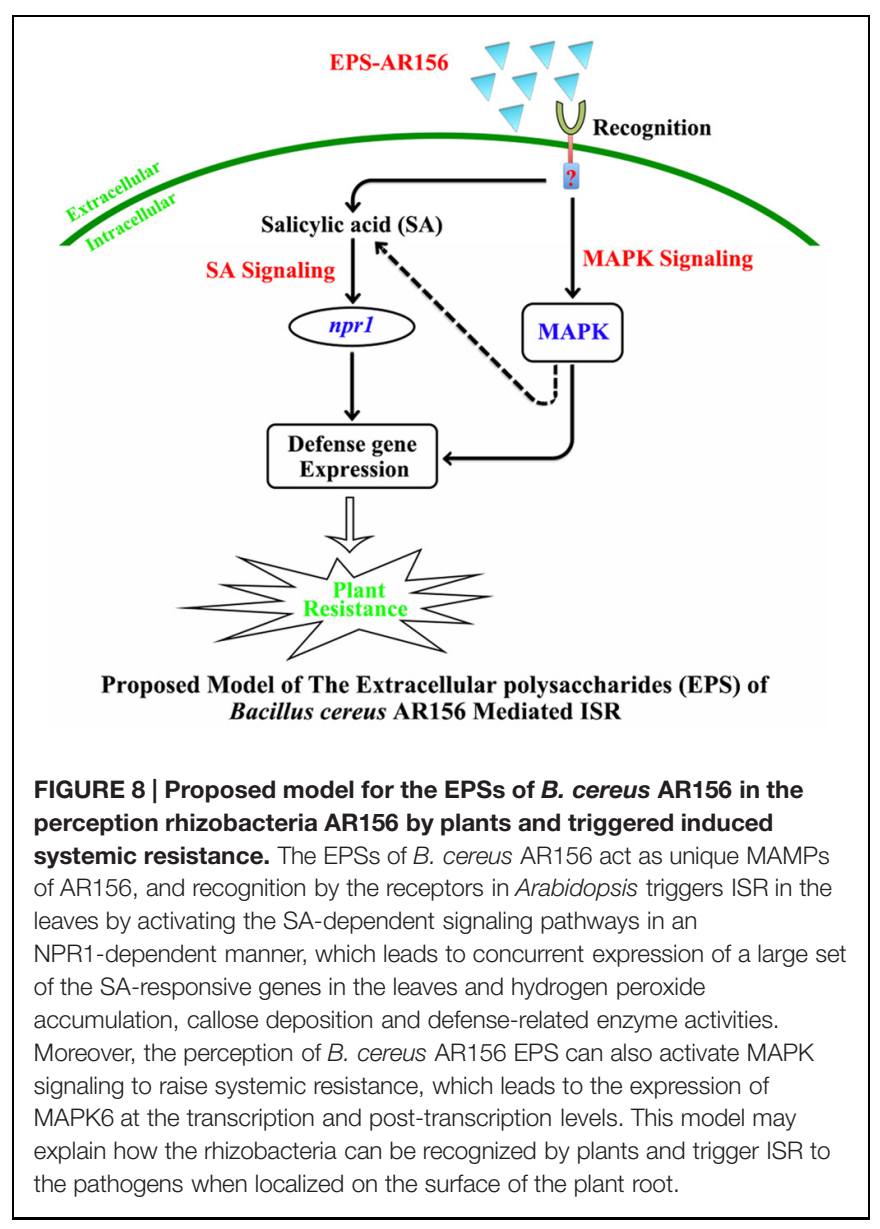

in agreement with the results of previous studies. However, in our previous study, it was found that colonization of Arabidopsis roots by AR156 enhanced resistance against a broad-spectrum disease and that AR156 could elicit ISR by simultaneously activating the SA and JA/ET two signaling pathways (Niu et al., 2011). However, in our study, the JA/ET-dependent defense responses were not potentiated by $B$. cereus AR156 EPS upon Pst DC3000 infection. Therefore, how was JA/ET-dependent signaling activated by AR156 during the ISR process? According to our results, in addition to the $B$. cereus AR156 EPS, there must be other MAMPs that facilitate perception and trigger ISR by activating the JA/ET-dependent signaling pathway.

Plants have evaluated series of mechanisms to help themselves against oomycete, fungal, bacterial, and viral infections. All these defense responses firstly start with the perception of the invading pathogen by PRRs, which can connect with PAMPs (Bittel and Robatzek, 2007; Segonzac and Zipfel, 2011). General elicitors such as flagellin (flg22), peptidoglycan (PGN), elongation factor $\mathrm{Tu}$ (EF-Tu), Ax21 (Activator of XA21-mediated immunity in rice), lipopolysaccharides (LPS), $\beta$-glucans from oomycetes and fungal chitin are recognized by plant membrane surface localized PRRs. Series of PAMPs and their corresponding PRRs have been identified in these years. (Newman et al., 1995, 2013; Umemoto et al., 1997; Felix et al., 1999; Lee et al., 2001; Kunze et al., 2004; Gust et al., 2007; Miya et al., 2007). Our study is the first to show that the EPSss of bacteria can act as novel MAMPs and induce visible cell death (Figure 1 and Supplementary Figure S1), cellular defense responses such as ROS production and callose deposition and defense-related enzymes such as POD and SOD in the plants tested (Figures $\mathbf{4}$ and $\mathbf{5}$ and Supplementary Figure S3) to trigger ISR to pathogens (Figure 2). These findings suggest that the $B$. cereus AR156 EPS may connect with some perception receptors localized on surface of the plant cell membrane, then trigger ISR to pathogens.

Microbe-associated molecular patterns-triggered ISR is important in assisting plants to limit pathogen growth or generate signals, which were used for adaptation to secondary infections (Coll et al., 2011; Hao et al., 2014). Many reports have documented that MAMPs, including flg22, can induce plant defense responses. However, to be able to implement this functionality, recognition by PRRs is necessary. A wellknown PRR is the Arabidopsis receptor kinase FLS2, which can recognizes a bacterial flagellin protein (flg22), which contains a conserved 22-amino acid N-terminal sequence. FLS2 consist of an LRR domain (extracellular leucine-rich repeat), a cytoplasmic kinase domain and a trans-membrane domain (Chinchilla et al., 2006; Li et al., 2014). The LRR domain can perceive flg22 and rapidly recruits to $\mathrm{BAK} 1$, which was another $\mathrm{LRR}$ receptor-like kinase (Chinchilla et al., 2007; Heese et al., 2007; Schulze et al., 2010; Li et al., 2014). In this study, we did not identify the receptors that could recognize $B$. cereus AR156 EPS. However, to better understand the function of EPS in the interaction between plants and rhizobacteria, receptor identification will be the focus of our future studies.

However, investigations of the chemical compositions and molecular structures of EPS are important to establish their functional relationship (Jin et al., 2014). Therefore, in this study, we also analyzed the characteristics and composition of EPS extracted from $B$. cereus AR156 that could act as a MAMPs. The results of IR spectral analysis showed that the EPS molecules contained different functional groups, such as hydroxyl, alkane, and carbonyl groups (Supplementary Figure S5). This information will be helpful in identifying the abovementioned receptors.

Some protein kinases belong to the mitogen-activated kinases (MAPKs) family has been demonstrated as signal transduction components in a variety of processes in plants (Nühse et al., 2000). A complete Arabidopsis MAPK cascade consisting of MEKK1, MPK3/ MPK6, and MKK4/MKK5, may be activated in response to flg22 was identified in recent years (Asai et al., 2002). In our study, we also demonstrated that the EPS extracted from $B$. cereus AR156 could activate the MAPK cascade in response to Pst DC3000 infection. At the transcription and protein levels, we found that the expression of MPK6 could be increased by B. cereus AR156 EPS treatment in Arabidopsis (Figure 7).

How were the $B$. cereus AR156 EPS perceived by plants, and what was their role in the process of $B$. cereus AR156-ISR? In this study, we identified $B$. cereus AR156 EPS as novel MAMPs that could be perceived by some PRRs and activated plant resistance to pathogens. A new model of the signal transduction cascade of EPS-mediated ISR in Arabidopsis was proposed (Figure 8). We found that the EPS of AR156 could be perceived by some 
PRRs then triggered ISR by activate the SA and MAPK signaling pathways with an NPR1-dependent manner, thus enhancing the level of induced disease resistance.

As far as we know, our study is the first to demonstrate that the EPSs of B. cereus AR156 can act as novel MAMPs and trigger ISR to the Pst DC3000 in Arabidopsis. Furthermore, this study is the first to illustrate how AR156 induces systemic resistance to Pst DC3000 in Arabidopsis. It is also the first to explain how the plant perceives the colonization of non-pathogenic bacteria and how rhizobacteria trigger ISR to plant pathogens when they are localized on the surface of the plant root. Future studies will focus on investigating how the EPSs are perceived by plants and how the early downstream of the plant defense response is activated and identifying the PRRs that can recognize the EPSs.

\section{ACCESSION NUMBERS}

The GenBank accession numbers for the genes mentioned in this article are as follows: At-npr1 (NM_105102), At-PR1 (NM_127025), At-PR2 (NM_115586), At-PR5 (NM_106161), AtPDF1.2 (NM_123809), At-MAPK6 (NM_129941), and At-BETATUB4 (NM_123801).

\section{AUTHOR CONTRIBUTIONS}

JC-H and GJ-H designed the study. JC-H, FZ-H, and XP performed the experiments. All authors analyzed the data. JC-H

\section{REFERENCES}

Asai, T., Tena, G., Plotnikova, J., Willmann, M. R., Chiu, W. L., Gomez- Gomez, L., et al. (2002). MAP kinase signalling cascade in Arabidopsis innate immunity. Nature 415, 977-983. doi: 10.1038/415977a

Bartels, S., Lori, M., Mbengue, M., van Verk, M., Klauser, D., Hander, T., et al. (2013). The family of Peps and their precursors in Arabidopsis: differential expression and colonization but similar induction of pattern-triggered immune responses. J. Exp. Bot. 64, 5309-5321. doi: 10.1093/jxb/ert330

Beckers, G. J., Jaskiewicz, M., Liu, Y., Underwood, W. R., He, S. Y., Zhang, S., et al. (2009). Mitogen-activated protein kinases 3 and 6 are required for full priming of stress responses in Arabidopsis thaliana. Plant Cell 21, 944-953.

Benhamou, N., and Belanger, R. R. (1998). Benzothiadiazole-mediated induced resistance to fusarium oxysporum f. sp. radicislycopersici in tomato. Plant Physiol. 118, 1203-1212. doi: 10.1104/pp.118.4.1203

Bethke, G., Pecher, P., Eschen-Lippold, L., Tsuda, K., Katagiri, F., Glazebrook, J., et al. (2011). Activation of the Arabidopsis thaliana mitogen-activated protein kinase mpk11 by the flagellin-derived elicitor peptide, flg22. Mol. Plant Microbe Interact. 25, 471-480. doi: 10.1094/MPMI-11-11-0281

Bittel, P., and Robatzek, S. (2007). Microbe-associated molecular patterns (MAMPs) probe plant immunity. Curr. Opin. Plant Biolol. 10, 335-341. doi: 10.1016/j.pbi.2007.04.021

Bleecker, A. B., Estelle, M. A., Somerville, C., and Kende, H. (1988). Insensitivity to ethylene conferred by a dominant mutation in Arabidopsis thaliana. Science 241, 1086-1089. doi: 10.1126/science.241.4869.1086

Boller, T., and Felix, G. (2009). A renaissance of elicitors: perception of microbe-associated molecular patterns and danger signals by pattern-recognition receptors. Annu. Rev. Plant Biol. 60, 379-406. doi: 10.1146/annurev.arplant.57.032905.105346

Bowling, S. A., Guo, A., Cao, H., Gordon, A. S., Klessig, D. F., and Dong, X. (1994). A mutation in Arabidopsis that leads to constitutive expression and GJ-H. wrote the article. All authors contributed to the research and manuscript and read and approved the final version of the manuscript. All authors agree to be accountable for all aspects of the work.

\section{ACKNOWLEDGMENTS}

We thank Profs. Zhou J. M. and Qi Y. J. (National Institute of Biological Sciences, Beijing) for kindly providing us with the seeds of Arabidopsis mutants, Prof. Dong H. S. (Nanjing Agricultural University, China) for the rifampicin-resistant pathogen Pst DC3000 and Arabidopsis ecotype Col-0 and transgenic line NahG, and Prof. Chai Y-L (Northeastern University, USA) for the kind suggestions regarding the design of some experiments. This research was supported by the National Natural Science Foundation of China (31471812), Jiangsu Province Agricultural Science and Technology Independent Innovation Fund Project $(\mathrm{CX}(15) 1044)$, and the Science and Technology Project of Jiangsu Province (BE2015364, BY2015071-04).

\section{SUPPLEMENTARY MATERIAL}

The Supplementary Material for this article can be found online at: http://journal.frontiersin.org/article/10.3389/fmicb. 2016.00664

of systemic acquired resistance. Plant Cell 6, 1845-1857. doi: 10.2307/ 3869912

Browse, J. (2009). Jasmonate passes muster: a receptor and targets for the defense hormone. Annu. Rev. Plant Biol. 60, 183-205. doi: 10.1146/annurev.arplant.043008.092007

Chinchilla, D., Bauer, Z., Regenass, M., Boller, T., and Felix, G. (2006). The Arabidopsis receptor kinase FLS2 binds flg22 and determines the specificity of flagellin perception. Plant Cell 18, 465-476. doi: 10.1105/tpc.105.036574

Chinchilla, D., Zipfel, C., Robatzek, S., Kemmerling, B., Nürnberger, T., Jones, J. D., et al. (2007). A flagellin-induced complex of the receptor FLS2 and BAK1 initiates plant defense. Nature 448, 497-500. doi: 10.1038/nature05999

Coll, N. S., Epple, P., and Dangl, J. L. (2011). Programmed cell death in the plant immune system. Cell Death. Differ. 18, 1247-1256. doi: 10.1038/cdd.2011.37

Conrath, U., Pieterse, C. M., and Mauch-Mani B. (2002). Priming in plant pathogen interactions. Trends Plant Sci. 7, 210-216. doi: 10.1016/S1360-1385(02)02244-6

Delaney, T. P., Uknes, S., Vernooij, B., Friedrich, L., Weymann, K., Negrotto, D., et al. (1994). A central role of salicylic acid in plant disease resistance. Science 266, 1247-1250. doi: 10.1126/science.266.5188.1247

Dodds, P. N., and Rathjen, J. P. (2010). Plant immunity: towards an integrated view of plant-pathogen interactions. Nat. Rev. Genet. 11, 539-548. doi: $10.1038 / \operatorname{nrg} 2812$

Dogan, N. M., Doganli, G. A., Dogan, G., and Bozkaya, O. (2015). Characterization of extracellular polysaccharides (EPS) produced by thermal bacillus and determination of environmental conditions affecting exopolysaccharide production. Int. J. Environ. 9, 1107-1116.

Felix, G., Duran, J. D., Volko, S., and Boller, T. (1999). Plants have a sensitive perception system for the most conserved domain of bacterial flagellin. Plant J. 18, 265-276. doi: 10.1046/j.1365-313X.1999.00265.x

Glazebrook, J. (2001). Genes controlling expression of defense responses in Arabidopsis-2001 status. Curr. Opin. Plant Biol. 4, 301-308. doi: 10.1016/S13695266(00)00177-1 
Gust, A., Biswas, R., Lenz, H. D., Rauhut, T., Ranf, S., Kemmerling, B., et al. (2007). Bacteria derived peptidoglycans constitute pathogen-associated molecular patterns triggering innate immunity in Arabidopsis. J. Biol. Chem. 282, 32338-32348. doi: 10.1074/jbc.M704886200

Hao, G., Pitino, M., Fang, D., Hong, L., Stover, E., and Duan, Y. (2014). Induction of innate immune responses by flagellin from the intracellular bacterium, 'candidatus liberibacter solanacearum'. BMC Plant Biol. 14:9. doi: 10.1186/s12870-014-0211-9

Haroun, B. M., Refaat, B. M., El-Menoufy, H. A., Amin, H. A., and El-Waseif, A. A. (2013). Structure analysis and antitumor activity of the exopolysaccharide from probiotic Lactobacillus plantarum NRRL B- 4496 In vitro and In vivo. J. Appl. Sci. Res. 9, 425-434.

Heese, A., Hann, D. R., Gimenez-Ibanez, S., Jones, A. M., He, K., Li, J., et al. (2007). The receptor-like kinase SERK3/BAK1 is a central regulator of innate immunity in plants. Proc. Natl. Acad. Sci. U.S.A. 104, 12217-12222. doi: 10.1073/pnas.0705306104

Hoagland, D. R., and Arnon, D. I. (1938). The water culture method for growing plants without soil. Calif. Agric. Exp. Stat. 347, 36-39.

Huang, W., and Liu, Z. M. (2013). Biosorption of $\mathrm{Cd}(\mathrm{II}) / \mathrm{Pb}$ (II) from aqueous solution by biosurfactant-producing bacteria: isotherm kinetic characteristic and mechanism studies. Colloids Surf. B. 105, 113-119. doi: 10.1016/j.colsurfb.2012.12.040

Huffaker, A., and Ryan, C. A. (2007). Endogenous peptide defense signals in Arabidopsis differentially amplify signalling for the innate immune response. Proc. Natl. Acad. Sci. U.S.A. 104, 10732-10736. doi: 10.1073/pnas.07033 43104

Hung, C. C., Santschi, P. H., and Gillow, J. B. (2005). Isolation and characterization of extracellular polysaccharides produced by Pseudomonas fluorescens Biovar II. Carbohydrate Polymers 6, 141-147. doi: 10.1016/j.carbpol.2005.04.008

Iriti, M., Rabotti, G., De Ascensao, A., and Faoro, F. (2003). Benzothiadiazole-induced resistance modulates ozone tolerance. J. Agric. Food Chem. 51, 4308-4314. doi: 10.1021/jf034308w

Jiang, C. H., Huang, Z. Y., Xie, P., Gu, C., Li, K., Wang, D. C., et al. (2015). Transcription factors WRKY70 and WRKY11 served as regulators in rhizobacterium B. cereus AR156-induced systemic resistance to Pseudomonas syringae pv. tomato DC3000 in Arabidopsis. J. Exp. Bot. 67, 157-174. doi: 10.1093/jxb/erv445

Jin, W., Li, Q., Li, M. M., Chen, T. H., Zhou, Y. F., and Yue, Z. B. (2014). Competitive adsorption of heavy metal by extracellular polymeric substances (eps) extracted from sulfate reducing bacteria. Bioresour. Technol. 163, 374-376. doi: 10.1016/j.biortech.2014.04.073

Jones, D. A., and Takemoto, D. (2004). Plant innate immunity direct and indirect recognition of general and specific pathogen-associated molecules. Curr. Opin. Immunol. 16, 48-62. doi: 10.1016/j.coi.2003.11.016

Katagiri, F., Thilmony, R., and He, S. Y. (2002). The Arabidopsis thalianapseudomonas syringae interaction. Arabidopsis Book 1:e0039. doi: 10.1199/tab.0039

Kauss, H., Fauth, M., Merten, A., and Jeblick, W. (1999). Cucumber hypocotyls respond to cutin monomers via both an inducible and a constitutive $\mathrm{H}_{2} \mathrm{O}_{2}$-generating system. Plant Physiol. 120, 1175-1182. doi: 10.1104/pp.120. 4.1175

Koch, E., and Slusarenko, A. (1990). Arabidopsis is susceptible to infection by a downy mildew fungus. Plant Cell 2, 437-445. doi: 10.2307/3869093

Kunze, G., Zipfel, C., Robatzek, S., Niehaus, K., Boller, T., and Felix, G. (2004). The $\mathrm{N}$ terminus of bacterial elongation factor Tu elicits innate immunity in Arabidopsis plants. Plant Cell 16, 3496-3507. doi: 10.1105/tpc.104.026765

Lakshmanan, V., Kitto, S. L., Caplan, J. L., Hsueh, Y. H., Kearns, D. B., Wu, Y. S., et al. (2012). Microbe-associated molecular patterns-triggered root responses mediate beneficial rhizobacterial recruitment in Arabidopsis. Plant Physiol. 160, 1642-1661. doi: 10.1104/pp.112.200386

Lee, J., Klüsener, B., Tsiamis, G., Stevens, C., Neyt, C., Tampakaki, A. P., et al. (2001). HrpZ(Psph) from the plant pathogen Pseudomonas syringae pv. phaseolicola binds to lipid bilayers and forms an ion-conducting pore in vitro. Proc. Natl. Acad. Sci. U.S.A. 98, 289-294. doi: 10.1073/pnas.98.1.289

Li, L., Li, M., Yu, L. P., Zhou, Z. Y., Liang, X. X., Liu, Z. X., et al. (2014). The fls2-associated kinase bik1 directly phosphorylates the nadph oxidase rbohd to control plant immunity. Cell Host Microbe 15, 329-338. doi: 10.1016/j.chom.2014.02.009
Lin, W. W., Li, B., Lu, D. P., Chen, S. X., Zhu, N., He, P., et al. (2014). Tyrosine phosphorylation of protein kinase complex bak1/bik1 mediates arabidopsis innate immunity. Proc. Natl. Acad. Sci. U.S.A. 111, 3632-3637. doi: $10.1073 /$ pnas.1318817111

Lu, D., Wu, S., Gao, X., Zhang, Y., Shan, L., and He, P. (2009). A receptorlike cytoplasmic kinase, bik1, associates with a flagellin receptor complex to initiate plant innate immunity. Proc. Natl. Acad. Sci. U.S.A. 107, 496-501. doi: 10.1073/pnas.0909705107

Mari-Anne, N., Thomas, S., Nielsen, J. T., and Gitte, E. (2013). MAMP (microbeassociated molecular pattern) triggered immunity in plants. Front. Plant Sci. 4:139. doi: 10.3389/fpls.2013.00139

Meziane, H., van Der Sluis, I., van Loon, L. C., Höfte, M., and Bakker, P. A. H. M. (2005). Determinants of Pseudomonas putida WCS358 involved in inducing systemic resistance in plants. Mol. Plant Pathol. 6, 177-185. doi: 10.1111/j.13643703.2005.00276.x

Miya, A., Albert, P., Shinya, T., Desaki, Y., Ichimura, K., Shirasu, K., et al. (2007). CERK1, a LysM receptor kinase, is essential for chitin elicitor signaling in Arabidopsis. Proc. Natl. Acad. Sci. U.S.A. 104, 19613-19618. doi: 10.1073/pnas.0705147104

Monaghan, J., and Zipfel, C. (2012). Plant pattern recognition receptor complexes at the plasma membrane. Curr. Opin. Plant Biol. 15, 349-357. doi: 10.1016/j.pbi.2012.05.006

Newman, M. A., Daniels, M. J., and Dow, J. M. (1995). Lipopolysaccharide from Xanthomonas campestris induces defense-related gene expression in Brassica campestris. Mol. Plant Microbe Interact. 8, 778-780. doi: 10.1094/MPMI8-0778

Newman, M. A., Sundelin, T., Nielsen, J. T., and Erbs, G. (2013). MAMPs (microbeassociated molecular patterns) triggered immunity in plants. Front. Plant Sci. 4:139. doi: 10.3389/fpls.2013.00139

Niu, D. D., Liu, H. X., Jiang, C. H., Wang, Y. P., Wang, Q. Y., Jin, H. L., et al. (2011). The plant growth-promoting rhizobacterium B. cereus AR156 induces systemic resistance in Arabidopsis thaliana by simultaneously activating salicylate-and jasmonate/ethylene-dependent signalling pathways. Mol. Plant Microbe Interact. 24, 533-542. doi: 10.1094/MPMI-09-10-0213

Nühse, T. S., Peck, S. C., Hirt, H., and Boller, T. (2000). Microbial elicitors induce activation and dual phosphorylation of the Arabidopsis thaliana mapk6. J. Biol. Chem. 275, 7521-7526. doi: 10.1074/jbc.275.11.7521

Pieterse, C. M., Van Wees, S. C., Hoffland, E., and Van Pelt, J. A., and Van Loon, L. C. (1996). Systemic resistance in Arabidopsis induced by biocontrol bacteria is independent of salicylic acid accumulation and pathogenesis-related gene expression. Plant Cell 8, 1225-1237. doi: 10.1105/tpc.8.8.1225

Pieterse, C. M., Van Wees, S. C. M., Ton, J., Van Pelt, J. A., and Van Loon, L. C. (2002). Signalling in rhizobacteria-induced systemic resistance in Arabidopsis thaliana. Plant Biol. 4, 535-544. doi: 10.1111/j.1438-8677.2011.00549.x

Pintor, A. M. A., Ferreira, C. I. A., and Pereira, J. C. (2012). Use of cork powder and granules for the adsorption of pollutants: a review. Water Res. 46, 3152-3166. doi: 10.1016/j.watres.2012.03.048

Rasul, S., Dubreuil-Maurizi, C., Lamotte, O., Koen, E., Poinssot, B., Alcaraz, G., et al. (2012). Nitric oxide production mediates oligogalacturonide-triggered immunity and resistance to Botrytis cinerea in Arabidopsis thaliana. Plant Cell Environ. 35, 1483-1499. doi: 10.1111/j.1365-3040.2012.02505.x

Reuber, T. L., Plotnikova, J. M., Dewdney, J., Rogers, E. E., Wood, W., and Ausubel, F. M. (1998). Correlation of defense gene induction defects with powdery mildew susceptibility in Arabidopsis enhanced disease susceptibility mutants. Plant J. 16, 473-485. doi: 10.1046/j.1365-313x.1998.00319.x

Schulze, B., Mentzel, T., Jehle, A. K., Mueller, K., Beeler, S., Boller, T., et al. (2010). Rapid heteromerization and phosphorylation of ligand-activated plant transmembrane receptors and their associated kinase BAK1. J. Biol. Chem. 285, 9444-9451. doi: 10.1074/jbc.M109.096842

Segonzac, C., and Zipfel, C. (2011). Activation of plant patternrecognition receptors by bacteria. Curr. Opin. Microbiol. 14, 54-61. doi: 10.1016/j.mib.2010.12.005

Singh, P. K., Singh, A. T., Kumar, A., and Singha, M. P. (2012). Mixed bacterial consortium as an emerging tool to remove hazardous trace metals from coal. Fuel 102, 227-230. doi: 10.1016/j.fuel.2012.06.039

Spoel, S. H., and Dong, X. (2012). How do plants achieve immunity? Defense without specialized immune cells. Nat. Rev. Immunol. 12, 89-100. doi: $10.1038 /$ nri3141 
Sreekanta, S., Bethke, G., Hatsugai, N., Tsuda, K., Ama T., Lin, W., Katagiri, F., et al. (2015). The receptor-like cytoplasmic kinase pcrk1 contributes to patterntriggered immunity against Pseudomonas syringae in Arabidopsis thaliana. New Phytol. 207, 78-90. doi: 10.1111/nph.13345

Staswick, P. E., Su, W., and Howell, S. H. (1992). Methyl jasmonate inhibition of root growth and induction of a leaf protein are decreased in an Arabidopsis thaliana mutant. Proc. Natl. Acad. Sci. U.S.A. 89, 6837-6840. doi: 10.1073/pnas.89.15.6837

Sun, A., and Li, Z. (2013). Regulatory role of nitric oxide in lipopolysaccharidestriggered plant innate immunity. Plant Signal. Behav. 8:e22554. doi: $10.4161 /$ psb. 22554

Takahashi, A., Casais, C., Ichimura, K., and Shirasu, K. (2003). HSP90 interacts with RAR1 and SGT1 and is essential for RPS2-mediated disease resistance in Arabidopsis. Proc. Natl. Acad. Sci. U.S.A. 100, 11777-11782. doi: 10.1073/pnas.2033934100

Torres, M. A., Dangl, J. L., and Jones, J. D. G. (2002). Arabidopsis gp91 (phox) homologues At-rbohD and At-rbohF are required for accumulation of reactive oxygen inter-mediates in the plant defense response. Proc. Natl. Acad. Sci. U.S.A. 99, 517-522. doi: 10.1073/pnas.012452499

Trdá, L., Boutrot, F., Claverie, J., Brulé, D., Dorey, S., and Poinssot, B. (2015). Perception of pathogenic or beneficial bacteria and their evasion of host immunity: pattern recognition receptors in the frontline. Front. Plant Sci. 6:219. doi: $10.3389 /$ fpls.2015.00219

Uknes, S., Mauch-Mani, B., Moyer, M., Potter, S., Williams, S., Dincher, S., et al. (1992). Acquired resistance in Arabidopsis. Plant Cell 4, 645-656. doi: 10.1105/tpc.4.6.645

Umemoto, N., Kakitani, M., Iwamatsu, A., Yoshikawa, M., Yamaoka, N., and Ishida, I. (1997). The structure and function of a soybean $\beta$-glucanelicitor-binding protein. Proc. Natl. Acad. Sci. U.S.A. 94, 1029-1034. doi: 10.1073/pnas.94.3.1029

Van der Ent, S., Verhagen, B. W., Van Doorn, R., Bakker, D., Verlaan, M. G., Pel, M. J., et al. (2008). MYB72 is required in early signalling steps of rhizobacteriainduced systemic resistance in Arabidopsis. J. Plant Physiol. 146, 1293-1304. doi: 10.1104/pp.107.113829

Van Loon, L. C., Bakker, P. A. H. M., and Pieterse, C. M. J. (1998). Systemic resistance induced by rhizosphere bacteria. Annu. Rev. Phytopathol. 36, 453483. doi: 10.1146/annurev.phyto.36.1.453

van Loon, L. C., Geraats, B. P. J., and Linthorst, H. J. M. (2006). Ethylene as a modulator of disease resistance in plants. Trends Plant Sci. 11, 184-191. doi: 10.1016/j.tplants.2006.02.005

Van Loon, L. C., and Van Strine, E. A. (1999). The families of pathogenesis related proteins, their activities, and comparative analysis of PR-1 type proteins. Physiol. Mol. Plant Pathol. 55, 85-97. doi: 10.1006/pmpp.1999.0213

Van Oosten, V. R., Bodenhausen, N., Reymond, P., Van Pelt, J. A., Van Loon, L. C., Dicke, M., et al. (2008). Differential effectiveness of microbially induced resistance against herbivorous insects in Arabidopsis. Mol. Plant Microbe Interact. 21, 919-930. doi: 10.1094/MPMI-21-7-0919

Van Wees, S. C. M., Van der, ENT. S., and Pieterse, C. M. J. (2008). Plant immune responses triggered by beneficial microbes. Curr. Opin. Plant Biol. 11, 443-448. doi: $10.1016 /$ j.pbi.2008.05.005

Vlot, A. C., Dempsey, D. M. A., and Klessig, D. F. (2009). Salicylic acid, a multifaceted hormone to combat disease. Annu. Rev. Phytopathol. 47, 177-206. doi: 10.1146/annurev.phyto.050908.135202
Wang, J., Li, Q., Li, M. M., Chen, T. H. Zhou, Y. F., and Yue, Z. B. (2014). Competitive adsorption of heavy metal by extracellular polymeric substances (EPS) extracted from sulfate reducing bacteria. Bioresour. Technol. 163, 374376. doi: 10.1016/j.biortech.2014.04.073

Ward, E. R., Uknes, S. J., Williams, S. C., Dincher, S. S., Wiederhold, D. L., Alexander, D. C., et al. (1991). Coordinate gene activity in response to agents that induce systemic acquired resistance. Plant Cell 3, 1085-1094. doi: 10.1105/tpc.3.10.1085

Wei, X., Fang, L. C., Cai, P., Huang, Q. Y., Chen, H., Liang, W., et al. (2011). Influence of extracellular polymeric substances (EPS) on Cd adsorption by bacteria. Environ. Pollut. 159, 1369-1374. doi: 10.1016/j.envpol.2011. 01.006

Yamaguchi, Y., Huffaker, A., Bryan, A. C., Tax, F. E., and Ryan, C. A. (2010). PEPR2 is a second receptor for the Pep1 and Pep2 peptides and contributes to defense responses in Arabidopsis. Plant Cell 22, 508-522. doi: 10.1105/tpc.109. 068874

Yedidia, I., Shoresh, M., Kerem, Z., Benhamou, N., Kapulnik, Y., and Chet, I. (2003). Concomitant induction of systemic resistance to Pseudomonas syringae pv. lachrymans in cucumber by Trichoderma asperellum (T-203) and accumulation of phytoalexins. Appl. Environ. Microbiol. 69, 7343-7353. doi: 10.1128/AEM.69.12.7343-7353.2003

Zhang, H., Xie, X., Kim, M. S., Kornyeyev, D. A., Holaday, S., and Paré, P. W. (2008). Soil bacteria augment Arabidopsis photosynthesis by decreasing glucose sensing and abscisic acid levels in planta. Plant J. 56, 264-273. doi: 10.1111/j.1365-313X.2008.03593.x

Zhang, J., Li, W., Xiang, T., Liu, Z., Laluk, K., Ding, X., et al. (2010). Receptor-like cytoplasmic kinases integrate signalling from multiple plant immune receptors and are targeted by a Pseudomonas syringae effector. Cell Host Microbe. 7, 290-301. doi: 10.1016/j.chom.2010.03.007

Zhang, J., Shao, F., Cui, H., Chen, L., Li, H., Zou, Y., et al. (2007). A Pseudomonas syringae effector inactivates MAPKs to suppress PAMPs-Induced immunity in plants. Cell Host Microbe 1, 175-185. doi: 10.1016/j.chom.2007. 03.006

Zhang, J., and Zhou, J. M. (2010). Plant immunity triggered by microbial molecular signatures. Mol. Plant 3, 783-793. doi: 10.1093/mp/ssq035

Zhang, X. M., Zhao, H. W., Gao, S., Wang, W. C., Katiyar-Agarwal, S., Huang, H., et al. (2011). Arabidopsis Argonaute 2 regulates innate immunity via miRNA393*-mediated silencing of a Golgi-localized SNARE gene, MEMB12. Mol. Cell 42, 356-366. doi: 10.1016/j.molcel.2011.04.010

Zipfel, C., Robatzek, S., Navarro, L., Oakeley, E., Jones, J. D. G., Felix, G., and Boller, T. (2004). Bacterial disease resistance in Arabidopsis through flagellin perception. Nature 428, 764-767. doi: 10.1038/nature02485

Conflict of Interest Statement: The authors declare that the research was conducted in the absence of any commercial or financial relationships that could be construed as a potential conflict of interest.

Copyright (C) 2016 Jiang, Fan, Xie and Guo. This is an open-access article distributed under the terms of the Creative Commons Attribution License (CC BY). The use, distribution or reproduction in other forums is permitted, provided the original author(s) or licensor are credited and that the original publication in this journal is cited, in accordance with accepted academic practice. No use, distribution or reproduction is permitted which does not comply with these terms. 